\title{
Effectiveness of a Polyphenolic Extract (Lippia Citriodora and Hibiscus Sabdariffa) on Appetite Regulation in Overweight and Obese Grade I Population: A 8 weeks Randomized, Double-Blind, Cross-Over, Placebo-Controlled Trial
}

\section{Ana Serna}

Universidad Catolica San Antonio de Murcia Facultad de Ciencias de la Salud

Javier Marhuenda ( $\boldsymbol{\sim}$ jmarhuenda@ucam.edu )

Universidad Católica San Antonio de Murcia Facultad de Ciencias de la Salud https://orcid.org/00000001-8239-0193

\section{Raúl Arcusa}

Universidad Catolica San Antonio de Murcia Facultad de Ciencias de la Salud

\section{Silvia Pérez-Piñeiro}

Universidad Catolica San Antonio de Murcia - Campus de los Jeronimos

Maravillas Sánchez-Macarro

Universidad Catolica San Antonio de Murcia - Campus de los Jeronimos

Desiree Victoria-Montesinos

Universidad Catolica San Antonio de Murcia - Campus de los Jeronimos

\section{Fernando Cánovas}

Universidad Catolica San Antonio de Murcia - Campus de los Jeronimos

Jonathan Jones

Monteloeder

Nuria Caturla

Monteoloder

Javier López-Román

Universidad Catolica San Antonio de Murcia - Campus de los Jeronimos

\section{Research}

Keywords: Hibiscus Sabadarrifa, Lippia Citriodora, Apetite Sensation, Polyphenols, Leptin

Posted Date: July 29th, 2020

DOl: https://doi.org/10.21203/rs.3.rs-47978/v1 
License: (c) (i) This work is licensed under a Creative Commons Attribution 4.0 International License. Read Full License

Version of Record: A version of this preprint was published at European Journal of Nutrition on September 30th, 2021. See the published version at https://doi.org/10.1007/s00394-021-02678-x. 


\section{Abstract}

Background. Polyphenols have shown capacity to improve appetite sensation, leading to enhanced control of body weight. However, despite being related with hunger-related hormones, metabolic and mechanism is not well known.

Methods. The effectiveness of a nutraceutical composed of extract to Lippia citriodora and Hibiscus sabdarrifa (Lc-Hs) for controlling satiety and hunger was analyzed in a placebo controlled (Pla) clinical intervention. The study was divided in two 60 days periods separated by 30 days length washout period. At the end of each period, volunteers ( $n=33$; both sexes) were proposed to eat an ad-libitum meal. Meanwhile, appetite sensation was determined by visual analog scales at different times. Moreover, blood extraction was performed to evaluate hunger-related hormones (insulin, leptin, ghrelin, adiponectin, GLP-1 and peptide YY) and glycemic and lipid profile.

Results. A decrease in appetite sensation was observed in Lc-Hs group, showing higher satiety quotient $(\mathrm{Pla}=3.36 \pm 2.33 \% / \mathrm{kcal} ; \mathrm{Lc}-\mathrm{Hs}=5.53 \pm 2.91 \% / \mathrm{kcal} ; \mathrm{p}<0.0001)$. Area under the curve was higher in Pla compared to Lc-Hs during the test, from baseline to minute 240 (240 (Pla $9136.65 \pm 2261.46 \%$ x min ${ }^{-1}$; Lc-Hs $8279.73 \pm 2745.71 \% \times \mathrm{min}^{-1} ; \mathrm{p}<0.014$ ). Leptin values varied from baseline (Pla $12.36 \pm 1.98$ $\mathrm{ng} / \mathrm{mL} ; \mathrm{Lc}-H s 13.13 \pm 1.99 \mathrm{ng} / \mathrm{mL}$ ) to the end of the study (Pla $12.60 \pm 2.02 \mathrm{ng} / \mathrm{mL}$; Lc-Hs $12.06 \pm 2.05$ $\mathrm{ng} / \mathrm{mL} ; p<0.047)$. GLP-1 values varied $(p<0.001)$ in Lc-Hs group from baseline $(4.34 \pm 0.49 \mathrm{ng} / \mathrm{mL})$ to the end of the study $(3.23 \pm 0.52 \mathrm{ng} / \mathrm{mL})$.

Conclusion: The supplementation with the Lc-Hs extract decreases appetite sensation in overweight and obese population, reducing calorie intake after an ad-libitum meal. Due to variation on hunger-related hormones and the relationship between satiety feeling, it would be interesting to develop future research focused on the variation of the hormones themselves.

\section{Background}

According to the World Health Organization, overweight and obesity are known as abnormal or excessive accumulation of body fat that is harmful to health, and unfortunately has become a worldwide epidemic in the 21 st century, especially in the last decades (1-3). Excess of body fat, is widely associated with non-communicable diseases including; hypertension, type II diabetes, cardiovascular diseases, hyperlipidemic, non-alcoholic fatty liver and various types of cancer (4-7). An increase in fat mass could be summarized in a reductionist way as an imbalance between caloric intake and energy expenditure. However it may also due to many factors such as genetics or psychological disorders (7). Natural products are an alternative to pharmacological drugs and can represent a fate alternative with minimal or no side effects $(8,9)$.

Appetite plays an important role in food consumption, influencing hunger and therefore caloric intake (10). It is defined as desire to consume food, which disappears once food intake takes place and it is followed by satiety feeling (11). Such sensations are triggered in the hypothalamus, which regulates the 
centers of hunger and satiety (12) which have neurotransmitters and hormones receptors that modulate eating behavior. These substances include those that stimulate appetite (orexigenics) such as ghrelin, and those that inhibit it (anorexigenic) such as insulin, leptin, adiponectine, peptide YY and GLP-1(13).

The interest in plant-derived polyphenols are due to their antiviral, antitumoral, antiatherogenic, antiinflamatory, antihypertensive, antilipogenic and antioxidant capacities. However, the mechanisms are not well known (14-16). Scientific literature shown that certain plan-derivate extracts such a Hibiscus sabadariffa, Lippia citriodora extracts can modulate different metabolic pathways and activating the AMPK pathway which favor lipolysis and therefore fat loss (17). Previous studies have shown that Hibiscus sabdariffa have an effect on the expression of pre-pandial hormones (18), containing a large amount of polyphenols that provide proven health benefits (19), but its potential as a satiety agent is not deeply studied.

We hypothesized that chronic consumption of a polyphenolic extract composed of Lippia citriodora and Hibiscus sabdariffa (LC-Hs) could have a synergistic effect on appetite regulation in overweight and obese people.

\section{Material And Methods \\ 2.1 Trial design}

The study consisted of a randomized controlled trial, double-blind, cross-over clinical trial with two branches depending on the product consumed experimental ( $\mathrm{Lc}-\mathrm{Hs}$ ) or placebo (Pla) and single-center (Fig. 1).

The present study had a length of 150 days divided into 2 allocations of 60 days separated by a washout period of 30 days. In the first phase subjects consumed the Lc-Hs or Pla and after the wash-out period the groups were crossed. Each subject was assigned a code generated by a software generator (Epidat v4.1 Epidat, Spain) allocating them to one of the groups. Both the researchers and the subjects did not know which group subjects belonged to.

\subsection{Participants}

A total of 36 healthy subjects of both sexes participated in the study, of which 33 completed the intervention and were included in the final analysis as depicted in Fig. 2. Subjects had to meet all inclusion criteria (age between 18-65 years old, both sexes, body mass index (BMI) between 25$34.9 \mathrm{~kg} / \mathrm{m}^{2}$, weight maintained in the last three months, do not modify nicotinic habits and absence of disease) and any of the exclusion criteria (chronic diseases, illness, thyroid dysfunction, allergies, carrying out or intend to carry out any type of diet during the study and pregnant woman) Table 1 shows demographic data of the volunteers from the study. After analyzing the aforementioned criteria, the protocol to be followed was carefully explained to the subjects by the investigators. Finally, subjects 
signed the informed consent in order to be included in the study. The study was conducted in accordance with the Declaration of Helsinki (randomized trial registration number (Clinicaltrials): NCT04105192).

Table 1

Demografic data.

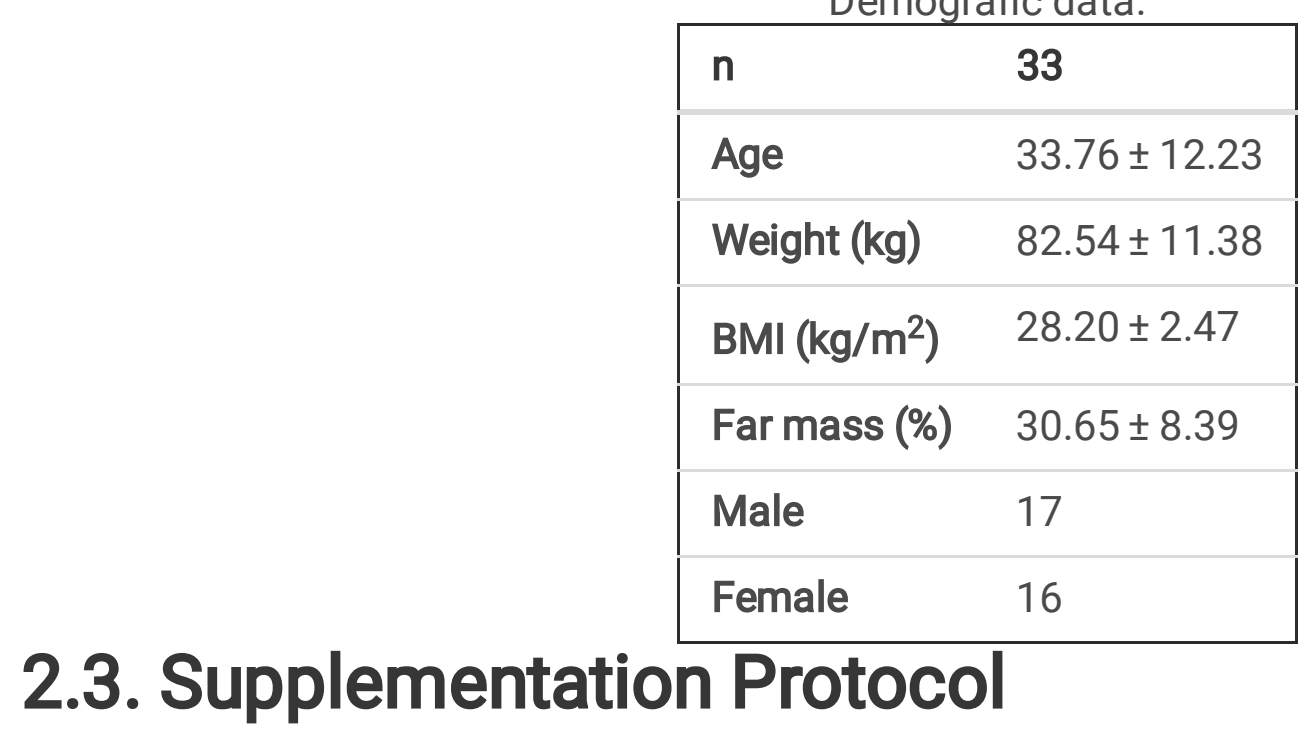

Lc-Hs (MetabolAid®, Monteleloeder S.L., Alicante, Spain) and Pla presented similar pharmaceutical form. Lc-Hs was composed by a mixture of extracts from Lippia citriodora and Hibiscus sabdariffa, while Pla contained crystalline microcellulose. The administration was oral consisting on 2 capsules/day, each capsule containing $250 \mathrm{mg}$ of either Lc-Hs or Placebo, before breakfast during a period of 60 days. At the end of each allocation, subjects were asked to return the empty blisters to check compliance of supplementation protocol. Same procedure was repeated after the crossover.

\subsection{Study settings}

Subjects came to laboratory several times. Study design is depicted in Fig. 1. In each phase subjects went to the laboratory 4 times. At baseline of each phase $(\mathrm{V} 1, \mathrm{~V} 3)$, blood samples were obtained from the antecubital veins of subjects in order to determinate hormonal and biochemistry (lipid and glucidic profile and safety parameters) analysis. After blood extraction, each subject received the product to consume (Lc-Hs or Pla) and an accelerometer (ActiGraph wGT3-BT. ActiGraph, Pensacola, FL, USA) was placed to evaluate their physical activity. Once the product was delivered and the subjects were instructed, a bioimpedance (Tanita BC-420M. Tanita Corporation, Arlington Heights, IL, USA) was performed to evaluate possible changes in body composition (weight, BMI, fat mass, and muscle mass). At the end of each phase (V2, V4), blood collection, evaluation of physical activity and body composition analysis were performed again.

To determine the efficacy of Lc-Hs, ad libitum appetite test and visual analog scale (VAS) were performed at the end of the two phases (V2 and V4). During these visits, subjects came to the laboratory on fasted and took the product $30 \mathrm{~min}$ before eating a standardized breakfast. After volunteers ate blood samples were taken and VAS were filled by subjects at baseline, which would continue until $270 \mathrm{~min}$ at different times $(0,15,30,60,90,120,180,240,270)$. At minute 240 a free buffet was served, in order to quantify 
an ad libitum intake. Nutritional value of the food served was determined using software (Dietsource v3.0). The nutritional composition of breakfast is showed in Table 2, being composed by bread ( $50 \mathrm{~g})$, ham $(30 \mathrm{~g})$, cheese $(25 \mathrm{~g})$, pineapple juice $(200 \mathrm{ml})$ and non-flavored yogurt $(125 \mathrm{~g})$. Moreover, the food chosen by the volunteers was weighed before and after the buffet lunch intake. Therefore, energy and macronutrients intake were determined for every volunteer from the quantitative measurement of food ingested.

Table 2

Nutritional value of

breakfast.

\section{\begin{tabular}{|ll|}
\hline Kcal & $\mathbf{4 1 7}$ \\
\hline CHO (g) & 47 \\
\hline Fiber (g) & 2 \\
\hline Protein (g) & 21 \\
\hline Lipids (g) & 15 \\
\hline
\end{tabular}}

Visual analog scales (VAS) were used to evaluate Overall Appetite Sensation (OAS) after the intake of every product under investigation. Volunteers reported their state of hunger, satiety and fullness on a $10 \mathrm{~cm}$ VAS by placing a vertical line on a scale that ranged, on the hunger scale, from "I have no hunger" to "I am the most hungry I have ever been"; on the satiety scale, from "I have no feeling of fullness" to "I'm as full as I've ever been"; on the fullness scale, from "I have no feeling of fullness" to "I have the greatest feeling of fulfillment I've ever had" and on the prospective food consumption scale (PFC) from "I have no desire to eat any food" to "I have the greatest desire to eat any food I've ever had". OAS was calculated as the average of the four individual scores: (satiety + fullness + (100 - PFC) + (100 - hunger)) / 4 (20).

VAS for each of the evaluated components of appetite, were completed by volunteers in the following times: before and immediately after the intake of product under investigation, and at 10", 20", 30", 40", 50", 60", 120", 180", 240" (immediately before ad-libitum meal) and 270" post-intake of foods under investigation (immediately after consumption of ad-libitum meal) (Fig. 3) $(21,22)$

OAS was calculated at every measurement interval, and the change in OAS was calculated as the difference between OAS baseline and OAS of each subsequent measurement using the following formula: Decrease of appetite = OAS pre-intake - OAS post-intake; in which the average OAS 60 min postintake was represented by the area under curve (AUC) at OAS (time $0,10,20,30,40,50$ y 60).

In the measurement of OAS, the area under the curve was calculated by summarizing the mean scores of pairs of adjacent time points and then calculating a weighted mean (weighted by the time difference of two time points). AUC was measured by the area under the curve of time course of OAS from minute 0 to 60 post-intake of product. 
Satiety evaluation, using VAS was carried out for each product in every volunteer who attended the present research.

The later-term effect on satiety of a food was determined from VAS, and the energy composition of products contained in the ad-libitum food consumption test, using the formula of satiety quotient (SQ).

SQ was calculated by the subtraction of the value "desire to eat" before the intake of the product under study, minus the average of "desire to eat" in the 60 minutes after intake of the product. This difference was divided by the energy values of the ingested ad-libitum food. By convention, the result of SQ is multiplied by 100 to obtain a more manageable range of values. Therefore, the resulting formula was: SQ $(\mathrm{mm} / 100 \mathrm{Kcal})=$ Decrease of appetite (defined as: (OAS pre-intake - Average OAS 60 min post-intake) / Energy of products under investigation (kcal) * 100), following the protocol used by Drapeau $\mathrm{V}$, et al (23, 24).

Where; CAL is total calories per $100 \mathrm{~g}$ (30 minimum), PR is grams protein per $100 \mathrm{~g}$ (30 maximum), DF is grams of dietary fiber per $100 \mathrm{~g}$ (12 maximum), TF is grams of total fat per $100 \mathrm{~g}$ (50 maximum).

\subsection{Biochemical analysis:}

Blood samples were analyzed in order to monitor satiety hormones (insulin, leptin, adiponectin, ghrelin, peptide tyrosine-tyrosine (PYY) and Glucagon-like Peptide-1 (GLP-1)), glycemic profile (glycemia, insulinemia, glycated hemoglobin (HbA1c), peripheral insulin resistance (HOMA-R)) and lipid profile (Total Cholesterol, LDL Cholesterol, HDL Cholesterol, triglycerides). Subjects had to arrive after a 12-hour fasting period, only allowing water intake until the previous 3 hours. In case of smokers, the last cigarette should have been smoked at least one hour before extraction. Moderate-high intensity exercise could not be performed in the previous 24 hours.

\subsection{Statistical analysis}

For quantitative variables, t-Student comparison was developed between both branches of the study, prior checking normality of the values. The qualitative variables were analyzed by means of a homogeneity test bases on the Chi-square distribution when the expected values made this possible and by Fisher's exact test otherwise. To analyze the differences between groups ( $\mathrm{Lc}-\mathrm{Hs}$ and Pla) a variance analysis for repeated measures (rANOVA) were carried out with intra-subject factor (time: basal and final or basal, 0 , $15,30,60,90,120,180,240$ and 270) and intersubject factor (LC-Hs group and Pla). In this way, differences were established in each of the variables analyzed, considering these factors. Moreover, Bonferroni test was performed for post-hoc analysis. The significance level used was 0.05 , and statistical analysis was carried out with the SPSS 21.0 software.

\section{Results}

\subsection{Satiety Assessment}


Due to the high predictive capacity, the main variable for the study of satiety was SQ. This quotient relates food intake to motivation to eat in the period after food intake, a relationship that cannot be determined by individual analysis of the amount of food consumed or ratings of motivation to eat. The implementation of $S Q$ is an additional aid to the determination of the satiating capacity of food, and provides information on the capacity of a food, a nutraceutical or a short-term appetite control drug. Interestingly, the treatment with the Lc-Hs extract resulted in enhanced SQ, leading to higher value compared with volunteers from Pla group $(p<0.0001)$. Therefore, SQ reported from the Lc-Hs group was $5.53 \pm 2.91 \% / \mathrm{kcal}$ compared to the volunteers from Pla group who reported minor value $(3.36 \pm$ $2.33 \% / \mathrm{kcal}$ ) (Fig. 4).

The remaining parameters to determine satiety also showed interesting results, being improved after treatment with Lc-Hs. Both Lc-Hs and Pla groups showed similar appetite sensation (AS) and satiety sensation parameters at baseline. However, after VAS accomplishment by volunteers, results showed a significant improvement in all parameters related to satiety and AS in volunteers treated with Lc-Hs compared to those treated with Pla. After a standardized breakfast intake at baseline (min - 30) VAS scales were given to the volunteers. During the first monitoring 2 hours it was found significant difference at the different control times during the scales, comparing Lc-Hs and Pla groups ( $\min 0$ : Pla (44.78 \pm 6.92) compared to Lc-Hs $(34.78 \pm 8.82)(\mathrm{p}<0.0001)$, $\min 15$ : Pla $(43.77 \pm 8.06)$ compared to Lc-Hs $(34.2 \pm$ 8.75) ( $<$ 0.0001), min 30: Pla $(40.58 \pm 9.33)$ compared to Lc-Hs $(32.54 \pm 8.90)(p<0.001)$, $\min 60:$ Pla (44.01 \pm 7.93$)$ compared to Lc-Hs $(38.13 \pm 9.29)$ compared to Lc-Hs $(p<0.005)$, min 90: Pla $(50.31 \pm 8.2)$ compared to Lc-Hs $(45.53 \pm 8.97)(p<0.002)$, min 120: Pla $(55.7 \pm 7.42)$ compared to Lc-Hs $(53.09 \pm 9.2)$ compared to Lc-Hs $(p<0.018))$. The evolution of AS and satiety is depicted in Fig. 5.

According to the aforementioned data, a large decrease evaluating the average of AS during the first hour was observed in volunteers treated with Lc-Hs compared to those treated with Pla $(p<0.0001)$.

Specifically, AS decreased from $73.09 \pm 12.89$ to $34.65 \pm 14.98$ in Lc-Hs and from $69.44 \pm 14.76$ to 42.76 \pm 13.21 in Pla. That variation is depicted in Fig. 6 .

AUC scores also showed the same correlation than the observed for satiety and AS. In this case, analyzing different periods of the test, increased AUS was observed in volunteers treated with Pla compared to those treated with Lc-Hs. During the first hour $(p<0.0001)$ AUC was higher in Pla volunteers $\left(2565.72 \pm 792.33 \% \mathrm{~min}^{-1}\right)$ while Lc-Hs group showed minor AUC $\left(2078.67 \pm 898.99 \% \mathrm{~min}^{-1}\right)$. However, the differences in AUC were decreasing as the minutes passed. Therefore, in the interval from min 60 to $\min 240(p=0.249)$ AUC of Pla $\left(10638.92 \pm 2413.30 \% \mathrm{~min}^{-1}\right)$ and Lc-Hs $\left(102565.65 \pm 2940.48 \% \mathrm{~min}^{-1}\right)$ groups showed to be close. Finally, due to the marked difference between treatment groups in the first 60 minutes, the overall AUC from baseline to $\min 240(p<0.014)$ was $9136.65 \pm 2261.46 \% \mathrm{~min}^{-1}$ for Pla and $8279.73 \pm 2745.71 \% \mathrm{~min}^{-1}$ for Lc-Hs.

It was observed that Lc-Hs group reported enhanced satiety and minor appetite than volunteers treated with $\mathrm{Pla}$, indicating better satiety response. Furthermore, despite the similar values observed of both 
treatment groups observed in the interval from min 60 to $\min 240$, the marked difference observed during the first hours lead to statistically significant differences along the following 4 hours (Fig. 7).

Finally, the caloric consumption during ad-libitum meal at the end of the 4 hours, showed minor ( $p<$ $0.004)$ energy consumption for volunteers treated with Lc-Hs $(774.44 \pm 247.77 \mathrm{kcal})$ compared to those treated with Pla (849.52 $\pm 246.54 \mathrm{kcal})$ (Fig. 8). These data together with SQ, reflect the relevance of AS and satiety as key factors in the number of calories consumed in a meal and the consequent feeling of satiety after that meal. Macronutrients content after ad-libitum intake was similar in both groups, leading to non-significant differences between them. The intake of protein, carbohydrates and fats in Pla group was $32.4 \pm 16.59,141.75 \pm 75.21$ and $44.3 \pm 18.65$ g respectively. In turn, the Lc-Hs group reported $34.95 \pm$ $18.84 \mathrm{~g}$ of protein $140.95 \pm 81.85 \mathrm{~g}$ of carbohydrates and $46.30 \pm 20.84 \mathrm{~g}$ of fats. The differences observed in macronutrients may be attributed due to inclusion of dietary fiber (mainly cellulose) as carbohydrates.

\subsection{Hormonal analysis of satiety}

The aforementioned parameters related to satiety and AS are subjective and given the improvement in satiety regulation, it could be feasible that these changes may be related to the expression of hormones and peptides regulating hunger and satiety. To carry out a hormonal analysis of satiety, both a long-term control during the study and a short-term control during the test were carried out.

Baseline values were similar in both groups for all hormones $(p>0,05)$. Table 3 shows the values obtained for long-term hormonal analysis. Anorexigenic hormones as insulin, adiponectin and PYY did not showed statistically significant intra group variation, neither in Lc-Hs or Pla groups $(p<0.05)$. However, leptin showed significant differences between Lc-Hs and Pla groups $(p<0.047)$, leading to minor leptin synthesis in Lc-Hs volunteers $(12,06 \pm 2,05 \mathrm{ng} / \mathrm{ml}$ than Pla group $(12,60 \pm 2,02 \mathrm{ng} / \mathrm{ml})$. In case of GLP-1, significant differences were observed comparing both Lc-Hs and Pla groups separately, leading to higher synthesis after the treatment of Lc-Hs group $(p<0.05)$. However, there was not found any difference in volunteers treated with Pla. On the other hand, the orexigenic hormone ghrelin commonly known as the hunger hormone (25) did not suffer statistically significant variation in neither Lc-Hs or Pla during the study. However, a downward trend was observed in the volunteers from the Lc-Hs group. In addition, the determination of insulin followed similar trend than the glycemic curve, according to plasmatic glucose concentration. 
Table 3

Evolution of hormonal analysis of subjects during the study.

\begin{tabular}{|llll|}
\hline & & Baseline & Final \\
\hline Insulinemia $(\mathrm{mU} / \mathrm{L})$ & CONTROL & $8.11 \pm 0.70$ & $8.62 \pm 0.77$ \\
\hline Leptin $(\mathrm{ng} / \mathrm{dL}) *$ & EXTRACT & $7.56 \pm 0.47$ & $7.77 \pm 0.54$ \\
\hline Adiponectin $(\mu \mathrm{g} / \mathrm{mL})$ & CONTROL & $12.36 \pm 1.98$ & $12.60 \pm 2.02$ \\
\hline EXTRACT & $13.13 \pm 1.99$ & $12.06 \pm 2.05$ \\
\hline Ghrelin $(\mathrm{ng} / \mathrm{mL})$ & CONTROL & $8.86 \pm 0.55$ & $8.64 \pm 0.59$ \\
\hline PYY $(\mathrm{pg} / \mathrm{mL})$ & EXTRACT & $8.58 \pm 0.56$ & $8.42 \pm 0.55$ \\
\hline GLP-1 $(\mathrm{ng} / \mathrm{mL})$ & CONTROL & $4.06 \pm 0.54$ & $4.11 \pm 0.49$ \\
\hline & EXTRACT & $4.08 \pm 3.87$ & $3.87 \pm .056$ \\
\hline \multirow{2}{*}{$\begin{array}{l}\text { Means significant statistical differences } p<0.05 \text { between groups. ** Means significant statistical } \\
\text { differences } p<0.001 \text { intra-group. }\end{array}$} & CONTROL & $55.27 \pm 8.93$ & $52.79 \pm 9.45$ \\
\hline
\end{tabular}

To the best of our knowledge, this is the first study to relate satiety measured by both hormones and satiety scales at different times during a stablished time period between meals. Considering evolution is important due to certain hormones such as ghrelin or GLP-1 have short active life span, regulating the amount of food consumed in a certain meal. Analyzing the evolution at different times during the test there was not found significant difference between groups in most of hormones (Fig. 9). However, plasmatic variation of adiponectin varied significantly at minute 180 during the test $(p<0.05)$, leading to higher concentration in volunteers treated with Pla $(8.77 \pm 0.55 \mu \mathrm{g} / \mathrm{mL})$ than Lc-Hs group $(8.21 \pm$ $0.5 \mu \mathrm{g} / \mathrm{mL}$ ). GLP-1 values were normalized from baseline. The Fig. 9 shows the treatment with Lc-Hs as determinant factor for the increase of GLP-1 from min 15 (12.39\%) Lc-Hs (1.33 \pm 0.21$)$ Pla (1.20 \pm 0.19$)$ until the end of the test $(22.36 \%) \mathrm{Lc}-\mathrm{Hs}(1.26 \pm 0.17)$ Pla $(1.03 \pm 0.16)$.

\subsection{Blood Parameters}

Obese and overweight population is commonly diagnosed with metabolic syndrome, so clinical and biochemical parameters need to be closely monitored. Table 4 shows glycemic and lipidemic profile of volunteers at baseline and at the end of the study (long-term) from both groups. At baseline no significant differences were observed between groups $(p>0.05)$ and remained stable after 8 weeks, so no significant 
changes were observed for the glycemic values during the study. Regarding $\mathrm{HbA} 1 \mathrm{c}$, the only remarkable variation occurred intra-group in the Lc-Hs group only $(p<0.009)$.

Table 4

Evolution of biochemical blood parameters of subjects during the study.

\begin{tabular}{|c|c|c|c|}
\hline & & Baseline & Final \\
\hline \multirow[t]{2}{*}{ Glycemia (mg/dL) } & CONTROL & $95.13 \pm 3.76$ & $97.13 \pm 3.31$ \\
\hline & EXTRACT & $94.12 \pm 2.39$ & $95.64 \pm 2.07$ \\
\hline \multirow[t]{2}{*}{ HbA1c (\%) } & CONTROL & $4.94 \pm 0.07$ & $5.01 \pm 0.09$ \\
\hline & EXTRACT** & $4.98 \pm 0.07$ & $4.90 \pm 0.06$ \\
\hline \multirow[t]{2}{*}{ HOMA-IR } & CONTROL & $1.92 \pm 0.18$ & $2.06 \pm 0.19$ \\
\hline & EXTRACT & $1.75 \pm 0.11$ & $1.84 \pm 0.13$ \\
\hline \multirow[t]{2}{*}{ Total Cholesterol (mg/dL) } & CONTROL & $186.96 \pm 5.91$ & $187.47 \pm 7.89$ \\
\hline & EXTRACT & $190.97 \pm 5.55$ & $182.90 \pm 6.06$ \\
\hline \multirow[t]{2}{*}{ LDL (mg/dL)* } & CONTROL & $109.72 \pm 5.17$ & $113.08 \pm 5.85$ \\
\hline & EXTRACT & $115.33 \pm 5.85$ & $109.98 \pm 5.77$ \\
\hline \multirow[t]{2}{*}{ HDL (mg/dL)* } & CONTROL & $54.46 \pm 1.37$ & $53.46 \pm 1.45$ \\
\hline & EXTRACT & $54.94 \pm 1.42$ & $57.46 \pm 1.58$ \\
\hline \multirow[t]{2}{*}{ Triglycerides (mg/dL) } & CONTROL & $109.22 \pm 6.23$ & $109.06 \pm 5.35$ \\
\hline & EXTRACT & $103.90 \pm 5.94$ & $104.25 \pm 4.98$ \\
\hline
\end{tabular}

In turn, lipid profile showed minor but remarkable changes. There is a downward trend for cholesterol and LDL values after the consumption of the product under study. The plasmatic variation of LDL cholesterol was significantly minor in volunteers from Lc-Hs group compared to Pla $(p<0.032)$. On the other hand, $\mathrm{HDL}$ cholesterol increased after the treatment with Lc-Hs compared to Pla, showing statistically significant differences $(p<0.008)$. However, triglyceride and total cholesterol values, remained at similar values than observed at baseline, regardless the treatment group.

\subsection{Biompedance and body composition}

Biompedance is a fast, secure, non-invasive and easy to apply method to evaluate body composition (26). Biompedance values began in similar conditions for both groups at baseline. BMI evolution did not show significant differences during the study, going from $28.03 \pm 2.53 \mathrm{~kg} / \mathrm{m}^{2}$ to $28.12 \pm 2.56 \mathrm{~kg} / \mathrm{m}^{2}$ in Pla and from $28.26 \pm 2.52 \mathrm{~kg} / \mathrm{m}^{2}$ to $27.98 \pm 2.62 \mathrm{~km} / \mathrm{m}^{2}$ showing a downward trend in Lc-Hs (Fig. 10). 
According to the scientific literature, it is convenient to evaluate body weight in its different components, especially separate fat mass and fat-free mass (FFM) (27). Figure 11 and Fig. 12 depicted evolution of fat mass and FFM respectively

Fat mass values evolution during the study were from $25.06 \pm 7.68 \mathrm{~kg}$ to $25.04 \pm 7.68 \mathrm{~kg}$ for Pla, and from $25.44 \pm 7.41 \mathrm{~kg}$ for Lc-Hs Pla and $24.51 \pm 7.14$ for Lc-Hs) showing significant differences only in Lc-Hs $p$ $<0.002$ intra-subject. For FFM values evolution during the study were from $54.61 \pm 10.82 \mathrm{~kg}$ to $54.53 \pm$ $10.72 \mathrm{~kg}$ for Pla and from $54.44 \pm 10.88 \mathrm{~kg}$ to $54.86 \pm 11.08 \mathrm{~kg}$ for Lc-Hs not showing significant differences.

The results showed a reduction in fat mass in Lc-Hs groups and maintenance of FFM and BMI compared to Pla.

\subsection{Physical Activity}

In order to reduce the error caused by personal differences in physical activity, sedentary volunteers were exclusively recruited. The measurement of METs by the accelerometer revealed that subjects from both placebo and experimental groups maintained the same physical activity during the study. Regarding Pla group, values ranged $(p=0.418)$ from $1.7 \pm 0.3$ MET at baseline to $1.8 \pm 0.3$ MET at the end of the study. In turn, the experimental group showed similar values $(p=0.842)$ both at baseline $(1.7 \pm 0.4 \mathrm{MET})$ and at the end of the study $(1.7 \pm 0.3 \mathrm{MET})$. That fact supports that changes observed in subjects consuming the Lc-Hs extract may be a consequence of such consumption and not a change in physical activity habits.

\section{Discussion}

Despite the use of caloric deficit through changes in diet or physical activity, the obese population has enormous difficulties in losing or maintaining weight and/or improving certain endocrine parameters. Therefore, considering the attributed effects of polyphenols in an obese population, different products could helping improve the previous results related to obesity treatment.

The scientific literature about polyphenols has been focused on their antioxidant capacity, but also in their possible use for the treatment of obesity (28). In this regard, the present clinical research reports the efficacy of the polyphenols contained in an Lc-Hs extract.

Hunger and satiety are regulated in the hypothalamus by complex network of neural pathways and the neuroendocrine system through central and peripheral molecular signals, gastrointestinal hormones, cytosines, metabolic intermediates, and nutrients. The regulating system can may have an orexigenic effect by activating anabolic pathways responsible for maintaining or gaining weight through mechanisms which induce hunger and stimulate appetite. On the other hand, the regulating system can exert an anorexigenic effect, stimulating catabolic pathways that promotes weight loss, through mechanisms that increase energy expenditure and decrease food intake by gastric filling and increased satiety (29). 
The most noticeable effect observed during the monitoring of food intake was decreased satiety. Satiety is a necessary parameter regulating body weight control, since it is the most effective factor to achieve progressive and successful long-term weight loss. One of the most common factors during weight loss in obese or overweight patients is anxiety caused by a reduction in the volume of dietary food, which can lead to excessive intake. This situation is one of the main factors that compromise the effectiveness of the protocols of weight loss and lifestyle change established for the treatment of obesity and overweight.

Judging by the results of the present study, chronic intake of a nutraceutical Lc-Hs extract during 8 weeks increase satiety in overweight and obese population. The most noticeable effect was an increase in SQ, reducing caloric intake throughout the day. Is important to note that higher values represent greater satiety and lower values less satiety (30). SQ is considered a valid indicator of satiety due to considers the AS before meals and the caloric content of food. In addition, has been shown to be positively associated with energy intake $(31,32)$ being the higher $S Q$ value, the lower caloric consumption, as occurs in the present study. Another interesting insight is the observed decrease are AS during at least two hours after meal intake, and reduced AUC from baseline to 240 -being more pronounced from baseline to minute 60-. Furthermore, due to similar protein content after ad-libitum intake in both groups (Table 2), it can be can affirmed that lower caloric intake and improvement in SQ and satiety do not relies on higher protein intake, which is known for its greater satiating capacity (11). Recognizing that satiety is defined as the interval between meals as a function of elapsed time, and that it can be used to predict the next feeding episode (33), SQ in seems to predict ad-libitum intake in the next 3 hours, a normal time period between meals.

Results observed for satiety and hunger sensation are in agreement previous studies in overweight population that reported an improvement in satiety sensation the treatment with the same Hs-LC extract during 8 weeks (18). Other authors have reported that different polyphenols can exert a synergistic effect to enhance their potential benefit $(34,35)$. However, the bioavailability in the intestinal tract should be considered (36).

Research on polyphenols against obesity seems to be due to various mechanisms of action as; lower food intake, decrease lipogenesis, increase lipolysis, stimulate fatty acid $\beta$-oxidation, inhibit adipocyte differentiation and growth, attenuate inflammatory responses and suppress oxidative stress $(28,37)$. Mechanisms include; Increased peroxisome proliferator-activated receptor (PPAR- $\gamma$ ) which promotes acid $\beta$-oxidation (38), inhibition of synthesis of malonyl-Coa (39) fatty acids precursor, increased CPT-1 protein which facilitate transport of fatty acids into mitochondria (38), activation of AMP-activated protein kinase (AMPK) pathway improving the glucose uptake in the cell (40) and thus insulin resistance. For example, scientific evidence has sown that certain plan-derivate such a Hibiscus sabadarrifa or Lippia citriodora can modulate different metabolic pathways and have certain effects activating the AMPK pathway, favoring lipolysis and fat loss $(9,17)$.

The regulation of AS, hunger and satiety occur in the hypothalamus, main regulatory area in central nervous systems. The arcuate nucleus is the hypothalamus region that participates in the control of food 
intake and have specific receptors for a wide variety of hormones and peptides that circulate in blood (41). After analyzing the different blood samples, no long-term inter-subject significant differences were observed in different hormones such as insulin, adiponectin, PYY or Ghrelin. However, there are some tendencies that should be mentioned.

Ghrelin is synthesized in the gastric fundus and bloating of the stomach in the presence of a large volume of food (42) reduces its plasmatic concentration. In the present research, Ghrelin showed a downward trend that varies between Pla and Lc-Hs groups. In fact, Pla treatment led to acutest diminution of ghrelin concentration during the 90 first minutes after meal intake-. In turn, Lc-Hs treatment was not as effective for reducing ghrelin synthesis in the first 90 minutes after meal intake as Pla. However, it was able to achieve a homogeneous and stable decrease (plateau shape) along the 240 minutes of plasmatic monitorization. As observed previously, volunteers treated with Lc-Hs reduced their caloric consumption, which can be a consequence of the reduction in the volume of food consumed that would lead to minor reduction on plasmatic ghrelin (greater plasmatic concentration). Therefore, Lc-Hs treatment was able to reduce caloric intake and food volume, while reducing Ghrelin concentration homogeneously for 240 minutes which can explain the reduction on hunger observed above. Despite not obtaining statistically significant results, it seems evident that treatment with $\mathrm{Lc}-\mathrm{Hs}$ is able to reduce food intake, as shown in adlibitum intake, appetite sensation and Ghrelin concentration in overweight and obese patients. The present data reinforces the idea that an adjuvant treatment with polyphenols can favorably affect glucose intake and regulation, adipogénesis, lipolysis, lipid metabolism, appetite control and improve pathologies related to obesity due to AMPK pathway modulation $(9,18)$. As well as the practice of physical exercise that help to reach caloric deficit, may be the best strategy for the treatment of obesity given the nature of the disease (43).

The determination of Leptin resulted in decreased concentration in Lc-Hs group $(p>0,05)$, showing certain intra-subject significant decrease $(p<0,05)$ between baseline and final measurements. The same tendency was not observed in the acute part of the study due to the long-term effect of that hormone. Leptin is mainly synthesized in adipose tissue and is able to inhibit food intake, being the most important hormone for long-term maintenance of body weight. However, obese population may present Leptin resistance, mainly due to lipid-related inflammation (44). Considering this premise, the decrease in leptin levels can be explained by the loss of fat mass observed in patients treated with Lc-Hs, so that the secretory capacity of leptin would also be reduced due to a lower amount of adipose tissue. That reduction in adipose tissue could also be responsible of the decrease in low-grade inflammation that predominates in overweight or obese patient, which is part-responsible of leptin resistance (45). Despite the reduction in leptin levels, the satiety sensation of the volunteers treated with the Lc-Hs extract increased in comparison with the Pla group. This could be a consequence of reduced Leptin resistance, which leads at least the same effects on hunger control with minor Leptin secretion $(9,44)$.

Likewise, the variation during feeding test of adiponectin is not marked but noticeable. The mechanisms underlying obesity-related reduction in plasmatic adiponectin have not yet been described in detail. Moreover, obese inflamed adipose tissues have been shown to reduce adiponectin secretion from 
adipocytes, while fat mass and the number of adipocytes in the whole body markedly increase with obesity (46). The long-term study of adiponectin in the present study reported similar values than the previous literature regardless body fact variation along the long-term study, showing that caloric diet variation does not alter adiponectin levels over time $(38,47)$. It has also been reported that low caloric diets do not varies plasmatic adiponectin levels regarding short $(39,48)$ and intermediate $(40,49)$ time periods. However, other authors reported that long-term interventions increase plasmatic adiponectin, improving abdominal fat distribution and lipid metabolism independently of weight change (50). In fact, the mechanism underlying adiponectin and its role in obesity needs more study. Short-term part of the present study reported continued reduction until the ad-libitum lunch for both Pla and Lc-Hs. Meanwhile, previous studies have seen an increase in adiponectin (51). Therefore, the variation of adiponectin in the present study seems to be influenced in both short and long periods, showing different trends.

Furthermore, in obese subjects, GLP-1 (anorexigenic satiating incretin) concentration is low, so a decrease could be expected in obese and overweight population $(25,41)$. The acute part of the present study revealed similar values for both Pla and Lc-Hs groups, with no differences between them. Almost all the hormones presented similar baseline values, as shown in Fig. 9, in order to reach more significant results GLP-1 values was standardized from baseline. The standardization was necessary due to the differences observed at baseline that could be misleading. As can be observed, GPL-1 increased in the Lc-Hs group after the treatment, improving fullness and satiety that could explain the excellent SQ observed in that group. Therefore, in the present study GLP-1 seems to be mayor factor controlling satiety and desire to eat.

In turn, the long-term part of the study showed some minor differences, but there were not noticeable. GLP-1 is synthesized in intestinal L cells whose secretion depends on the presence of nutrients in the lumen of the small intestine. Once GLP-1 reaches circulation, it has a half-life of a few minutes, due to rapid degradation by the enzyme dipeptidyl peptidase-4 (52). Therefore, the long-term evolution of GLP-1 does not provide as much information about the control of hunger and satiety as does the short-term evolution. In fact, the scientific literature on the long-term effects of GLP-1 is an area yet to be explored.

Due to the improvements in lipid profile observed in in vitro an animal models (53), it seems desirable to measure these parameter in a human-based study. Meanwhile, glucose level was not improved during the present study; however, a significant reduction of glycated hemoglobin was observed in volunteers treated with Lc-Hs but not in Pla group. In contrast, LDL Cholesterol and HDL Cholesterol varied significantly after the treatment with Lc-Hs, leading to minor and higher plasmatic levels respectively. Meanwhile, total cholesterol showed a downward trend, but there was not found any significant variation for triglycerides. That variation in lipid profile may be due to the substances and antioxidant effects of the polyphenols present in Lc-Hs extract specially due to anthocyanins content $(54,55)$. In this study significant reductions in lipid levels were seen in hyperlipidemcic subjects after consumption of Hibiscus sabdariffa (56). 
Body composition was improved in the Lc-Hs group with a reduction in fat mass, not observing changes in FFM or BMI. It is essential to differentiate FFM from lean mass, due to many people misinterpret FFM value as if it were a muscle mass overestimating that value (26). FFM includes muscle mass, bone mass, skin mass, and residual mass. There were also no changes in quality of life test, as well as adverse al

tri in liver or kidney function after product intake (57). In this study, researchers found a reduction in fat mass (especially in the torso) after the consumption of 84 days of a Lc-Hs extract in similar population (58). In the present study, the BMI of the volunteers did not change along the whole study $(p>0,05)$; however, the reduction on fat mass and the increase in FFM reveals that the treatment with Lc-Hs is a possible treatment that prevents sarcopenia $(59,60)$.

Therefore, a polyphenolic extract based on Lippia citriodora and Hibiscus sabdarrifa improves the regulation of appetite in overweight population, mainly satiety. On the other hand, the lower leptin values were expected due to reduction in fat mass of subjects. In addition, the maintenance of FFM can produce a decrease in basal metabolism of the volunteers, favoring a possible lon-term weight reduction. This, together with hormonal and lipidemic changes observed in the study, may contribute to improvements in health.

\section{Conclusion}

In conclusion, the consumption of $500 \mathrm{mg} /$ day of mixed Lippia citriodora and Hibiscus sabdarrifa polyphenolic extract in the context of an isocaloric diet for 60 days in overweight subjects confirmed significant decrease on appetite sensation and body composition, with possible decrease of calorie after an ad-libitum meal, also improving lipidemic profile. Moreover, the increased satiety observed in the present study could be attributed to the changes observed in Leptine, Ghelin and GLP-1. However, despite the variation reported on hunger-related hormones, the present study was focused on satiety sensation but not on hormone regulation. Therefore, it would be interesting to develop future research with more appropriate methodology and focused on the variation of the hormones themselves as main research parameter.

\section{Abbreviations}

AMPK (AMP-activated protein kinase)

AS (Appetite Sensation)

BMI (Body Mass Index)

FFM (Fat Free Mass)

GLP-1 (Glucagon-like Peptide-1)

HbA1c (Glycated Hemoglobin) 
HOMA-R (peripheral insulin resistance)

Lc-Hs (Lippia citriodora and Hibiscus sabdarrifa)

OAS (Overall Appetite Sensation)

PFC (Prospective food consumption scale)

Pla (Placebo)

PPAR-y (peroxisome proliferator-activated receptor)

PYY (peptide tyrosine-tyrosine)

SQ (Satiety Quotient)

VAS (Visual analog Scale)

\section{Declarations}

Ethics approval and consent to participate: The study protocol was reviewed and approved by the UCAM.

Consent for publication: Not applicable.

Availability of data and material: The datasets generated and/or analyzed during the current study are not publicly available due to their commercial nature but are available from the corresponding author on reasonable request and with permission of the Royal Voluntary Service.

Competing interests: The authors declare no conflict of interest.

Funding: This research received external funding from the INNOPREFAT Project, GA 783838, in the framework of the Horizon 2020 Programme, $₫$ Natural Food Formulation for the Prevention and Treatment of Obesity and Metabolic Syndrome Obtained with Herbal Extracts $\rrbracket$.

Authors' contributions: Funding acquisition: N.C., J.J. and J.L.-R.; investigation: A.S, J.M. and J.L.-R.; methodology: J.M., S.P-P., R.A., A.S, D.V-M., M.S.M., and J.L.-R.; project administration: J.J.; resources: N.C.; supervision: F.C, J.M.; validation: J.L.-R.; writing, review and editing, J.M., R.A., and J.L.-R. All authors have read and agreed to the published version of the manuscript.

Acknowledgements: We thank to INNOPREFAT Project for allowing the development of the study.

\section{References}

1. Wyatt SB, Winters KP, Dubbert PM. Overweight and Obesity: Prevalence, Consequences, and Causes of a Growing Public Health Problem. Am J Med Sci [Internet]. 2006;331(4):166-74. Available from: 
http://dx.doi.org/10.1097/00000441-200604000-00002

2. Williams EP, Mesidor M, Winters K, Dubbert PM, Wyatt SB, Wyatt SB, et al. Overweight and Obesity: Prevalence, Consequences, and Causes of a Growing Public Health Problem. 2015;363-70.

3. Marie NG, Fleming T, Robingson M, Thomson B, Graetz N, Margono C, et al. E Funders Group Global , regional and national prevalence of overweight and obesity in children and adults 1980-2013: Lacent. 2014;384(9945):766-81.

4. Guh DP, Zhang W, Bansback N, Amarsi Z, Birmingham L, Anis AH. The incidence of co-morbidities related to obesity and overweight: A systematic review and meta-analysis. BMC Public Health. 2009;9:188.

5. Savino P. Obesidad y enfermedades no transmisibles relacionadas con la nutrición.Revista colombiana de cirugia. 2011;26(3):180-95.

6. Ohri-vachaspati P, Leviton L, Bors P, Brennan L, Brownson RC, Strunk S. Strategies Proposed by Healthy Kids, Healthy Communities Partnerships to Prevent Childhood Obesity. Prev Chronic Dis. 2012;9:1-10.

7. Ojulari OV, Lee SG, Nam J. Beneficial Effects of Natural Bioactive Compounds from Hibiscus sabdariffa L . on Obesity. Molecules. 2019;24(1):210.

8. Heber D. Herbal preparations for obesity: are they useful? Prim Care. 2003 Jun;30(2):441-63.

9. Lee Y-S, Yang W-K, Kim HY, Min B, Caturla N, Jones J, et al. Metabolaid(®) Combination of Lemon Verbena and Hibiscus Flower Extract Prevents High-Fat Diet-Induced Obesity through AMP-Activated Protein Kinase Activation. Nutrients. 2018 Sep;10(9).

10. Gibbons C, Finlayson G, Dalton M, Caudwell P. Metabolic Phenotyping Guidelines: Studying eating behaviour in humans. J Endocrinol. 2014;222(2):G1-12.

11. García-Flores CL, Martínez Moreno AG, Beltrán Miranda CP, Zepeda-Salvador AP, Solano Santos LV. Saciación vs saciedad: Reguladores del consumo alimentario. Rev Med Chil. 2017;145(9):1172-8.

12. John EH. Guyton y Hall. Tratao de Fisiología Médica. 13ª . Ed. Madrid: S.A. Elservier España; 2016.

13. Quitral V, Torres M, Velásquez M, Bobadilla M. Efecto de inulina en la saciedad en humanos. Perspectivas en Nutrición Humana. 2018;20(1):79-89.

14. Vendrame S, Klimis-zacas D. Anti-inflammatory effect of anthocyanins via modulation of nuclear factor- kB and mitogen-activated protein kinase signaling cascades. Nutr Rev. 2015;73(6):348-58.

15. Beltrán-debón R, Rull A, Rodríguez-sanabria F, Iswaldi I, Herranz-lópez M, Aragonès G. Phytomedicine Continuous administration of polyphenols from aqueous rooibos (Aspalathus linearis ) extract ameliorates dietary-induced metabolic disturbances in hyperlipidemic mice. Phytomedicine. 2011;18(5):414-24.

16. Li A, Li S, Zhang Y, Xu X, Chen Y, Li H. Resources and Biological Activities of Natural Polyphenols. Nutrients. 2014;6(12):6020-47.

17. Herranz-lópez $M$, Olivares-vicente $M$, Boix-castejón $M$, Caturla N. Differential effects of a combination of Hibiscus sabdariffa and Lippia citriodora polyphenols in overweight / obese subjects: A 
randomized controlled trial. 2019;(June 2018):1-12.

18. Boix-Castejón M, Herranz-López M, Pérez Gago A, Olivares-Vicente M, Caturla N, Roche E, et al. Hibiscus and lemon verbena polyphenols modulate appetite-related biomarkers in overweight subjects: a randomized controlled trial. Food Funct. 2018 Jun;9(6):3173-84.

19. Guardiola S, March N. Potencial terapéutico del Hibiscus sabdariffa: una revisión de las evidencias científicas [Therapeutic potential of Hibiscus sabdariffa: a review of the scientific evidence]. Endocrinol Nutr. 2014;61(5):274-295.

20. Hobden MR, Guérin-Deremaux L, Commane DM, Rowland I, Gibson GR, Kennedy OB. A pilot investigation to optimise methods for a future satiety preload study. Pilot feasibility Stud. 2017;3:61.

21. Klosterbuer AS, Thomas W, Slavin JL. Resistant starch and pullulan reduce postprandial glucose, insulin, and GLP-1, but have no effect on satiety in healthy humans. J Agric Food Chem [Internet]. 2012;60(48):11928-11934.

22. Wang XS, Neill MO, Thomas W, Slavin J. White and Brown Rice are Equally Satiating and More Satiating than Glucose Beverage. J Obes Weight Loss Ther [Internet]. 2013;3(202):2.

23. Drapeau V, Blundell J, Therrien F, Lawton C, Richard D, Tremblay A. Appetite sensations as a marker of overall intake. Br J Nutr. 2005 Feb;93(2):273-80.

24. Drapeau V, King N, Hetherington M, Doucet E, Blundell J, Tremblay A. Appetite sensations and satiety quotient: Predictors of energy intake and weight loss. Appetite. 2007;48(2):159-66.

25. Heber D, Nava-santana CA, Guerra-soto ADJ, Mendoza-vázquez G, Flores-chávez A, Nava A, et al. Reguladores neuroendocrinos y gastrointestinales del apetito y la saciedad. EL Resid [Internet]. 2010;60(6):468-87. Available from: http://www.elsevier.es/es-revista-endocrinologia-nutricion-12articulo-obesidad-analisis-etiopatogenico-fisiopatologicoS1575092212001283\%0Afile:///C:/Users/DELL/Desktop/NEUROPSICOLOGIA/reguladores neuroendocrinos del hambre.pdf\%0Ahttp://www.ajcn.org/cont

26. Alvero-Cruz JR, Gómez LC, Ronconi M, Vázquez RF, Manzanido JP.La biompedancia eléctrica como método de estimación de la composición corporal: normas prácticas de utilización. Revista Andaluza de medicina del deporte. 2011;4(4):167-74.

27. Moreira OC, Oliveira CEPD, Candia-Luján R, Romero-Pérez EM, Fernandez P. Métodos de evaluación de la masa muscular: una revisión sistemática de ensayos controlados aleatorios. Nutrición Hospitalaria. 2015;32(3):977-985.

28. Wang , N. Moustaid-Moussa , L. Chen , H. Mo , A. Shastri , R. Su , P. Bapat , I. Kwun and C. L. Shen , Novel insights of dietary polyphenols and obesity, J. Nutr. Biochem. 2014;25(1): 1 -18.

29. Hita G, Elvira M, Macías A, Gabriela K, Enríquez S. Regulación neuroendócrina del hambre , la saciedad y mantenimiento del balance energético.Investigación y salud. 2006;8(3):191-200.

30. Sanchez M, Darimont C, Panahi S, Drapeau V, Marette A, Taylor VH, et al. Effects of a Diet-Based Weight-Reducing Program with Probiotic Supplementation on Satiety Efficiency, Eating Behaviour Traits, and Psychosocial Behaviours in Obese Individuals. Nutrients. 2017 Mar;9(3). 
31. Green SM, Delargy HJ, Joanes D, Blundell JE. A satiety quotient: a formulation to assess the satiating effect of food. Appetite. 1997 Dec;29(3):291-304.

32. Drapeau V, King N, Hetherington M, Doucet E, Blundell J, Tremblay A. Appetite sensations and satiety quotient: predictors of energy intake and weight loss. Appetite. 2007 Mar;48(2):159-66.

33. Livingstone MBE, Robson PJ, Welch RW, Burns AA, Burrows MS, McCormack C. Methodological issues in the assessment of satiety. Näringsforskning. 2000;44(1):98-103.

34. Herranz-lópez M, Fernández-arroyo S, Pérez-sanchez A, Barrajón-catalán E, Beltrán-debón R, Abel J, et al. Phytomedicine Synergism of plant-derived polyphenols in adipogenesis: Perspectives and implications. 2012;19:253-61.

35. Herranz-lópez M, Barrajón-catalán E, Segura-carretero A, Menéndez JA, Joven J, Micol V. Lemon Verbena (Lippia Citriodora) Polyphenols Alleviate Obesity-Related distrubances in Hypertrophic Adipocytes Through AMPK-dependent Mechanisms. Phytomedicine. 2015;22(6):605-14.

36. Castañeda R, Cáceres A. Compuestos bioactivos y propiedades terapéuticas de los cálices de rosa de Jamaica (Hibiscus sabdariffa Linn.). Revista Científica de la Facultad de Ciencias Químicas y Farmacia. 2014;23(1):7-24.

37. Rupasinghe HPV, Sekhon-Loodu S, Mantso T, Panayiotidis MI. Phytochemicals in regulating fatty acid $\beta$-oxidation: Potential underlying mechanisms and their involvement in obesity and weight loss. Pharmacol Ther. 2016;165:153-63.

38. Jeon BT, Jeong EA, Shin HJ, Lee Y, Lee DH, Kim HJ, et al. Resveratrol attenuates obesity-associated peripheral and central inflammation and improves memory deficit in mice fed a high-fat diet. Diabetes. 2012 Jun;61(6):1444-54.

39. Aguirre L, Fernández-Quintela A, Arias N, Portillo MP. Resveratrol: anti-obesity mechanisms of action. Molecules. 2014 Nov;19(11):18632-55.

40. Chung JH, Manganiello V, Dyck JRB. Resveratrol as a calorie restriction mimetic: therapeutic implications. Trends Cell Biol. 2012 Oct;22(10):546-54.

41. Ochoa C, Muñoz G. Hambre,Apetito y Saciedad. Rev Cuba Aliment y Nutr [Internet]. 2014;24(2):26879. Available from: http://www.medigraphic.com/pdfs/revcubalnut/can-2014/can142k.pdf

42. Tremblay A, Bellisle F. Nutrients, satiety, and control of energy intake. Appl Physiol Nutr Metab. 2015;40(10):971-9.

43. Wadden TA, Bray GA. Handbook of obesity treatment. Guilford Publications; 2018.

44. Kelesidis T, Kelesidis I, Chou S, Mantzoros CS. Narrative review: the role of leptin in human physiology: emerging clinical applications. Ann Intern Med. 2010 Jan;152(2):93-100.

45. Clavijo M, Garcés F. Obesidad y resistencia a la leptina. Gaceta médica boliviana. 2010;33(1):63-68.

46. Maeda N, Funahashi T, Matsuzawa Y, Shimomura I. Adiponectin, a unique adipocyte-derived factor beyond hormones. Atherosclerosis. 2020 Jan;292:1-9.

47. Merl V, Peters A, Oltmanns KM, Kern W, Born J, Fehm HL, et al. Serum adiponectin concentrations during a 72-hour fast in over- and normal-weight humans. Int J Obes (Lond). 2005 Aug;29(8):998- 
1001.

48. Imbeault P, Pomerleau M, Harper ME, Doucet E. Unchanged fasting and postprandial adiponectin levels following a 4-day caloric restriction in young healthy men. Clin Endocrinol (Oxf). 2004 Apr;60(4):429-33.

49. Anderlová K, Kremen J, Dolezalová R, Housová J, Haluzíková D, Kunesová M, et al. The influence of very-low-calorie-diet on serum leptin, soluble leptin receptor, adiponectin and resistin levels in obese women. Physiol Res. 2006;55(3):277-83.

50. Ma W, Huang T, Zheng Y, Wang M, Bray GA, Sacks FM, et al. Weight-loss diets, adiponectin, and changes in cardiometabolic risk in the 2-year POUNDS Lost Trial. J Clin Endocrinol Metab. 2016;101(6):2415-22.

51. Nolde JM, Laupenmühlen J, Al-Zubaidi A, Heldmann M, Münte TF, Jauch-Chara K. Endocrine responses and food intake in fasted individuals under the influence of glucose ingestion. PLoS One. 2019;14(1).

52. Salvador J, Escalada FJ. Fisiología del GLP-1 y su papel en la fisiopatología de la diabetes mellitus tipo 2. Med Clin (Barc) [Internet]. 2014;143(Supl 2):2-7. Available from: http://dx.doi.org/10.1016/S0025-7753(14)70101-0

53. Ochani PC, Mello PD.Antioxidant and antihyperlipidemic activity of Hibiscus sabdariffa Linn. leaves and calyces extracts in rats. Indian J Exp Biol. 2009;47(April):276-82.

54. Crawford RS, Kirk EA, Rosenfeld ME, Leboeuf C, Chait A. Dietary antioxidants inhibit development of fatty streak lesions in the LDL receptor - deficient mouse. Arteriosclerosis, thrombosis and vascular biology. 1998;18(9):1506-1513.

55. Fraga CG, Croft KD, Kenndy DO, Tomás-Barverán F. The effects of polyphenols and other bioactives on human health. Food \& function. 2019;10(2):514-528.

56. Herández-Pérez F, Herrea-Arellan A. Tratamiento de la hipercolesterolemia con Hibiscus sabadariffa. Ensayo clinico aleatorizado controlado. Revista Médica del Instituto Mexicano del Seguro Social. 2011;49(5):469-480.

57. Vanltallie TB, Yang MU, Heymsfield SB, Funk RC, Boileau RA. Height-normalized indices of the body's fat-freee mass and fat mass: potentially useful indicators of nutritional status. The American journal of clinical nutrition. 1990;52(6):953-959.

58. Marhuenda J, Perez S, Victoria-montesinos D. Trial to Determine the E ff ectiveness a Polyphenolic Extract ( Hibiscus sabdari ff a and Lippia citriodora ) in. 2020;

59. Vela-barba CL. Papel de la comorbilidad en el impacto de la sarcopenia sobre la función musculoesquelética. Acta Médica Peruana. 2014;31(2):106-10.

60. García-González Al, Axtle-Serrano Z, López-Teros M, Szlejf C, Martínez-Ruiz A, Rosas-Carrasco O. Intervenciones clínicas en obesidad osteosarcopénica: alimentación, actividad física y psicológica. Revista Médica del Instituo Mexicano del Seguro Social. 2018;51(1):82-93.

\section{Figures}




\section{INTERVENTION}

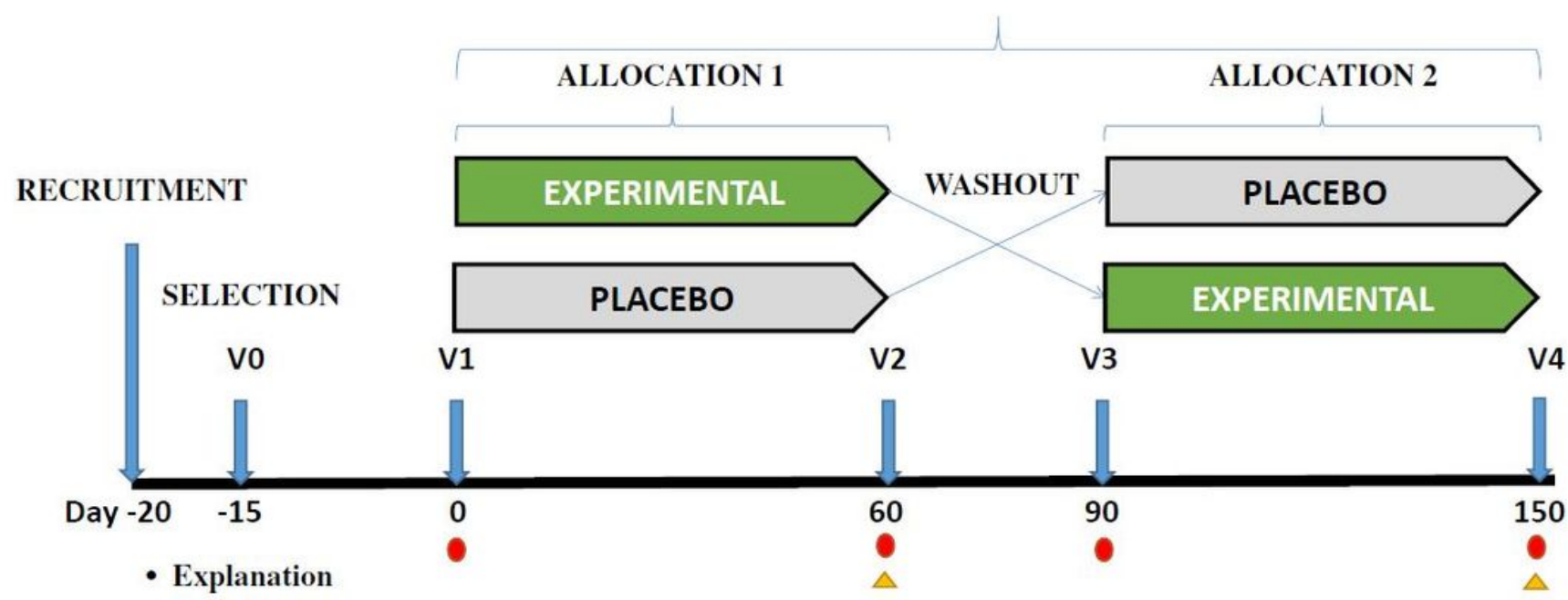

- Informed consent

- BMI check

- Meal test by VAS (V2, V4) $\triangle$

- Blood samples (V1, V2, V3, V4)

- Product Delivery (V1, V3)

- Product Return (V2, V4)

- Biompedance (V1, V2, V3, V4)

- Accelerometer (V1, V2, V3, V4)
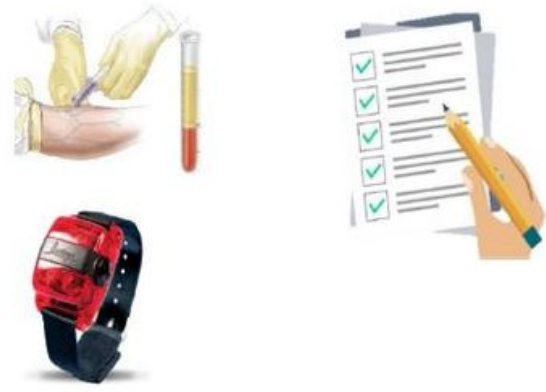

Figure 1

Graphic representation of the study design and some variables. Letter $\mathrm{V}$ means visit. 


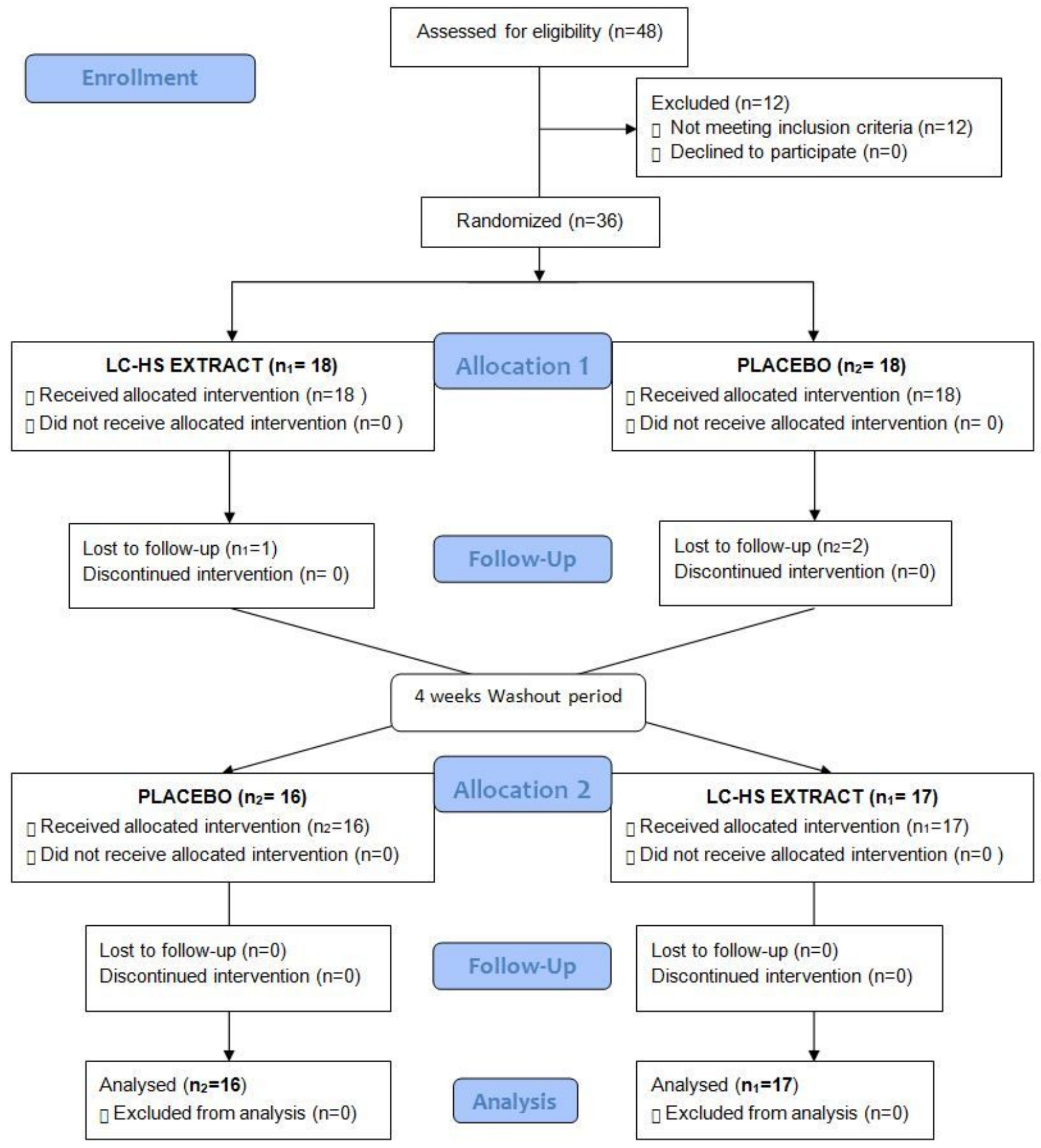

\section{Figure 2}

Flow chart. 


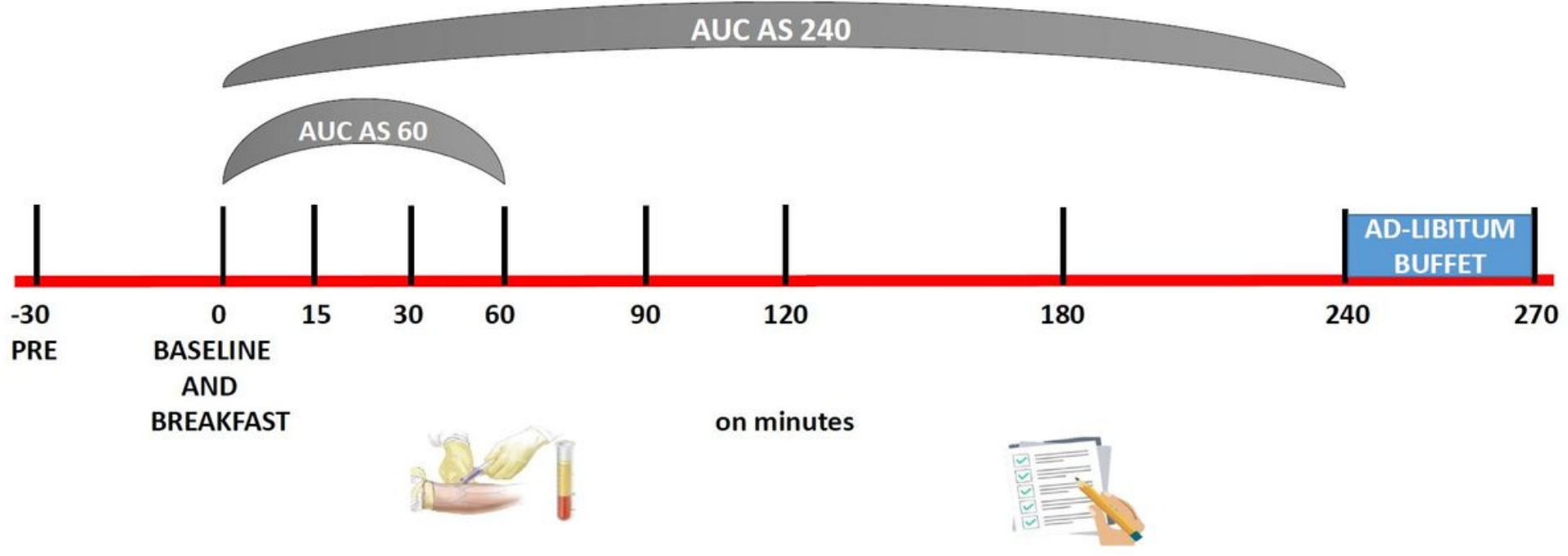

\section{Figure 3}

Instant on minutes (from baseline to min 270) where blood samples and VAS were performed during the study. 


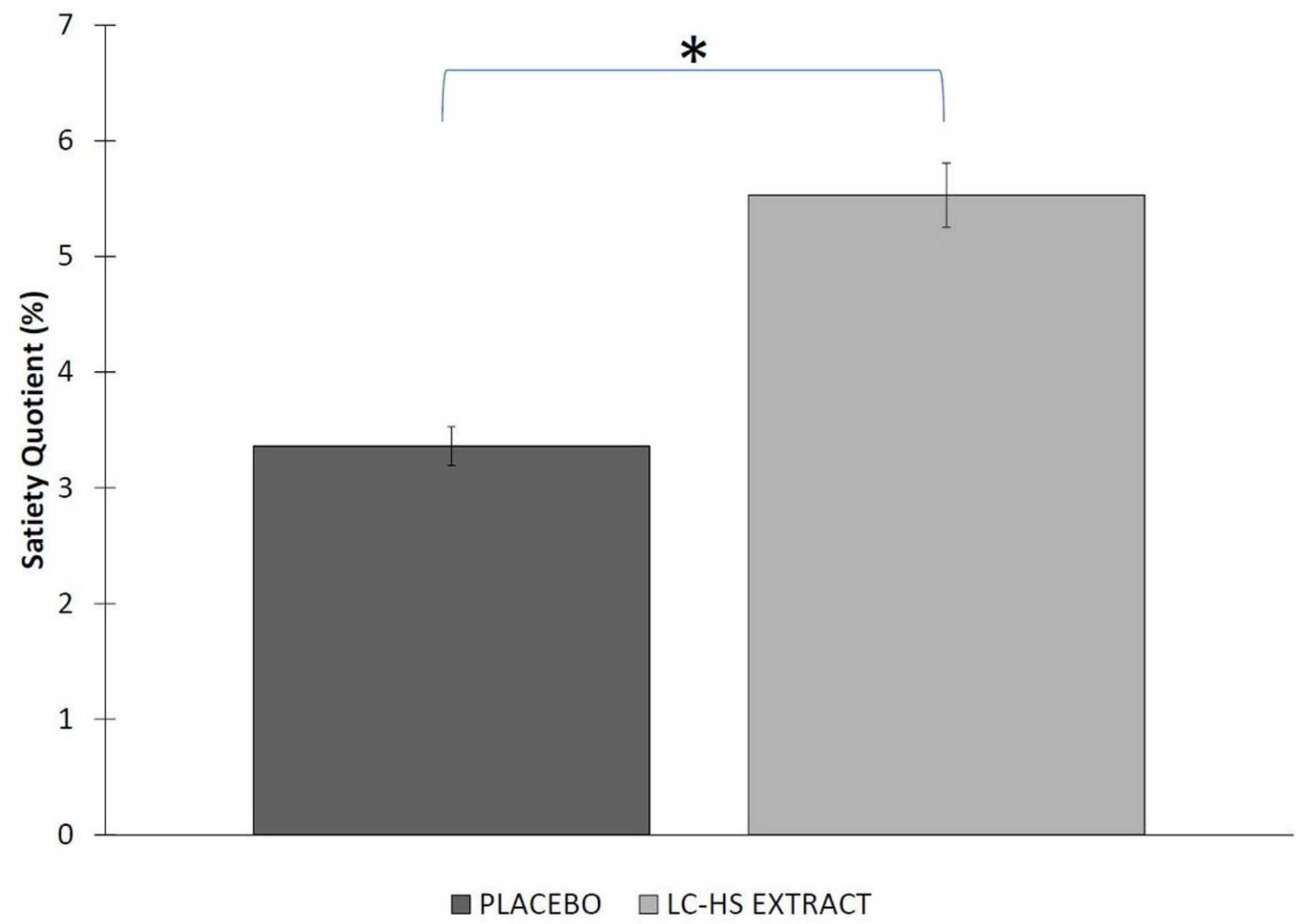

Figure 4

Satiety quotient evolution \%. * Means significant statistical differences between groups $p<0.0001$. 
$\leadsto$ PLACEBO $=$ LC-HS

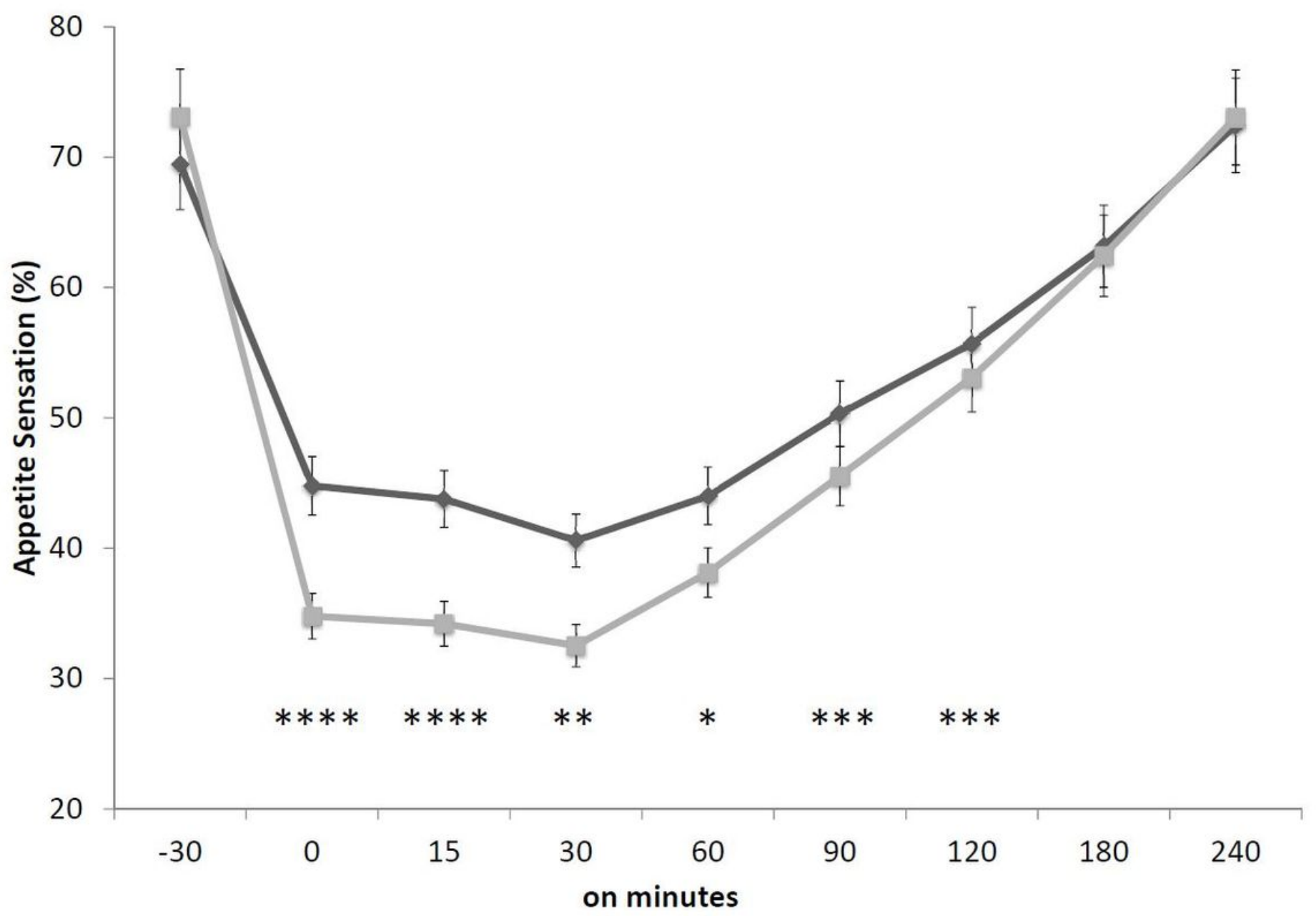

Figure 5

Appetite Sensation during the test. Appetite Sensation in different moments of the study until min 240. * Means significant differences between groups $p<0.05$. ** Means significant differences between groups $p<0.001$. ${ }^{* \star}$ Means significant differences between groups $p<0.002$. ${ }^{* \star \star \star}$ Means significant differences between groups $p<0.0001$. 


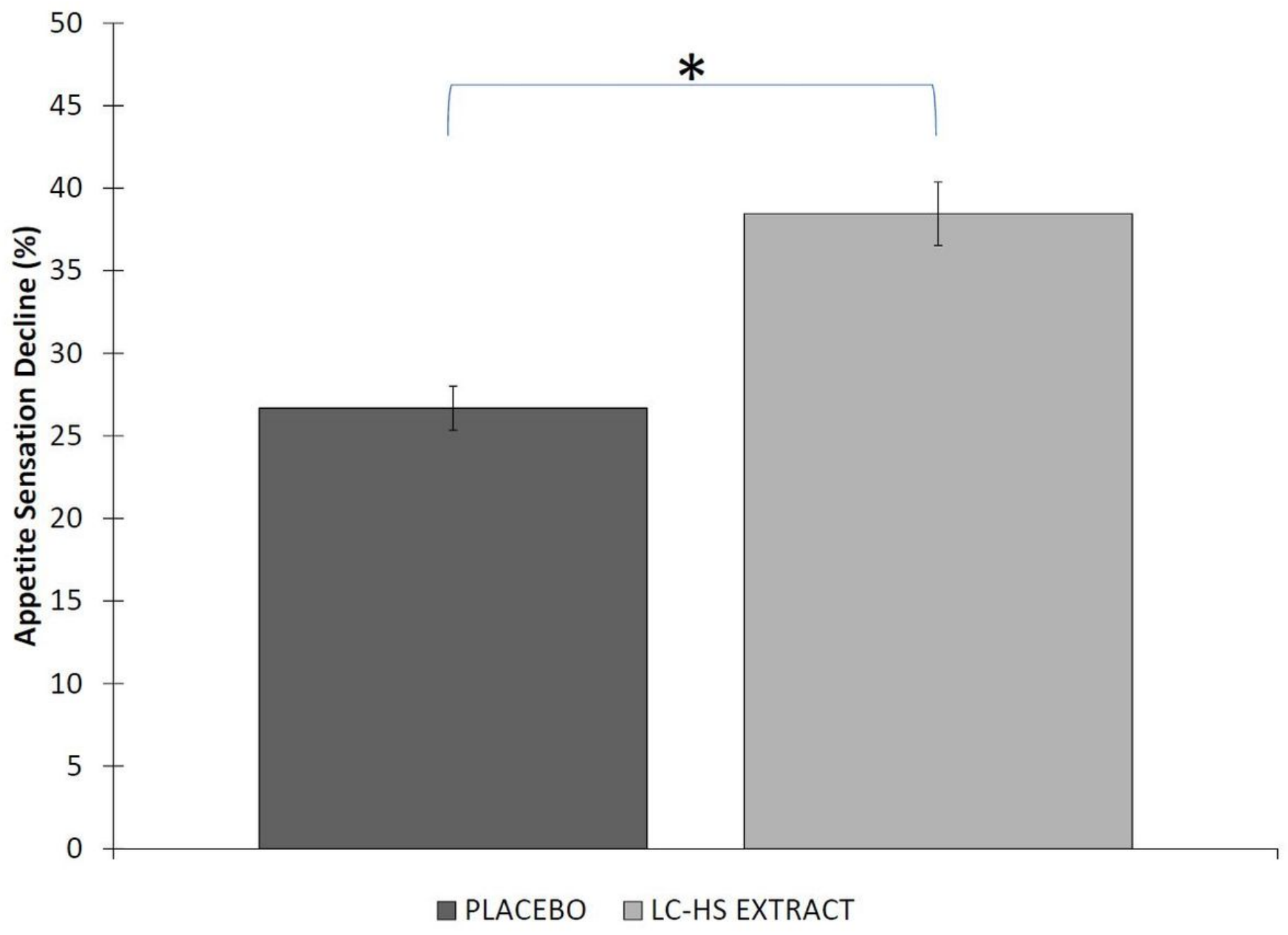

Figure 6

Decline of AS average from baseline to minute $60 .{ }^{*}$ Means significant statistical differences $p<0.0001$. 


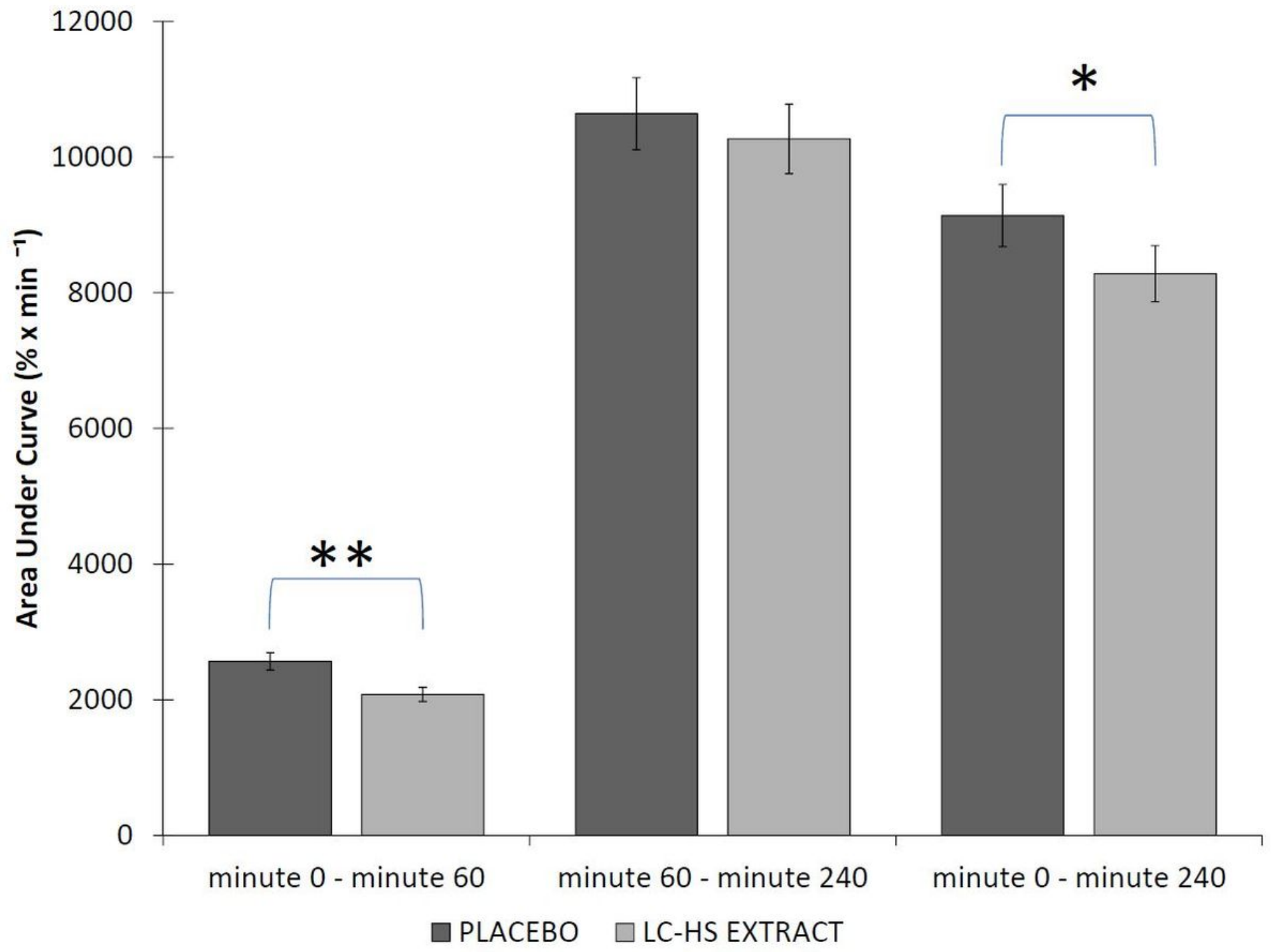

Figure 7

Area Under the Curve from placebo and extract during the test. * Means significant statistical differences $p<0.05$. ${ }^{*}$ Means significant differences between groups $p<0.001$. 


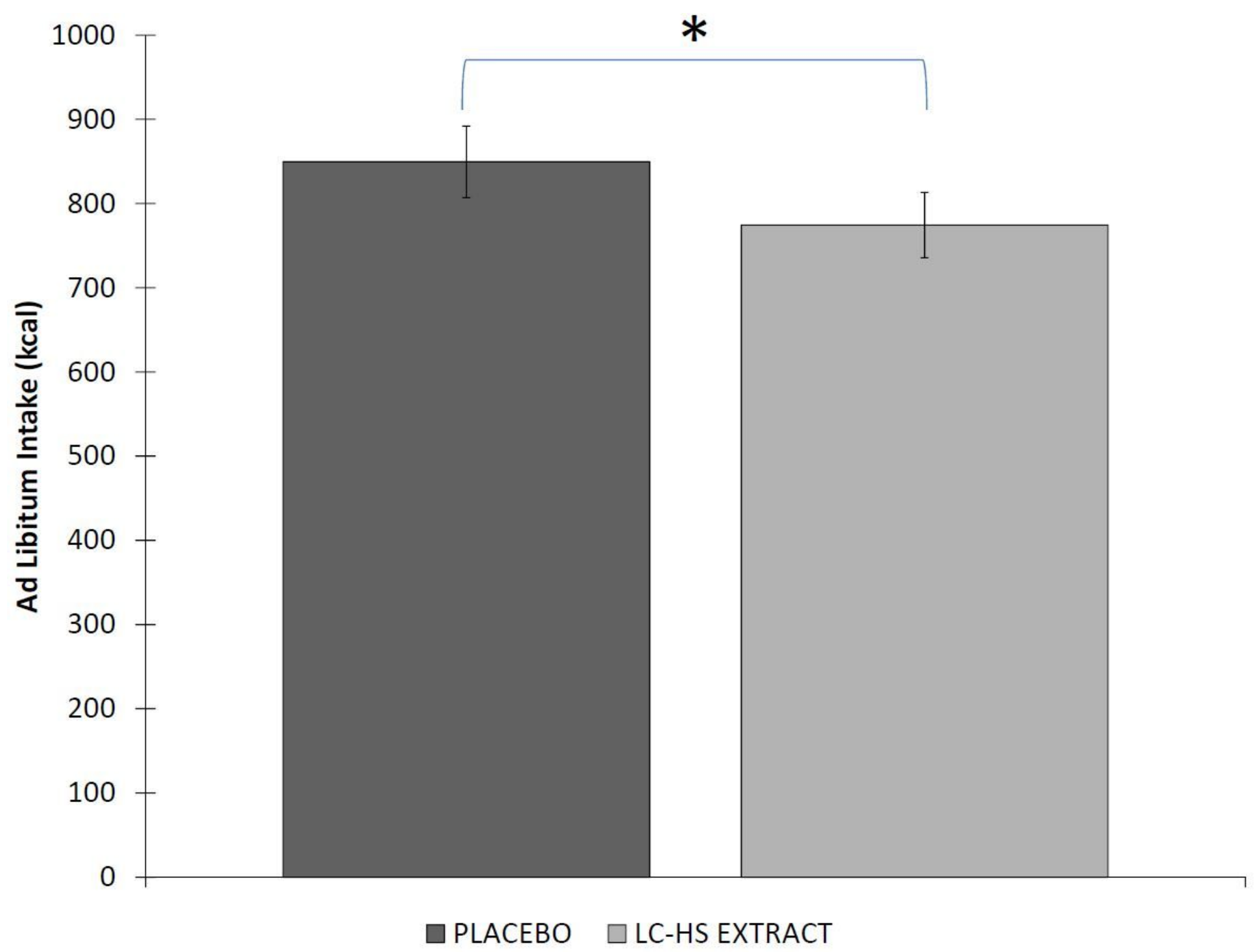

Figure 8

Quantity of kcal intake at minute 270 (Ad-libitum intake). * Means significant statistical differences between groups $p<0.004$. 

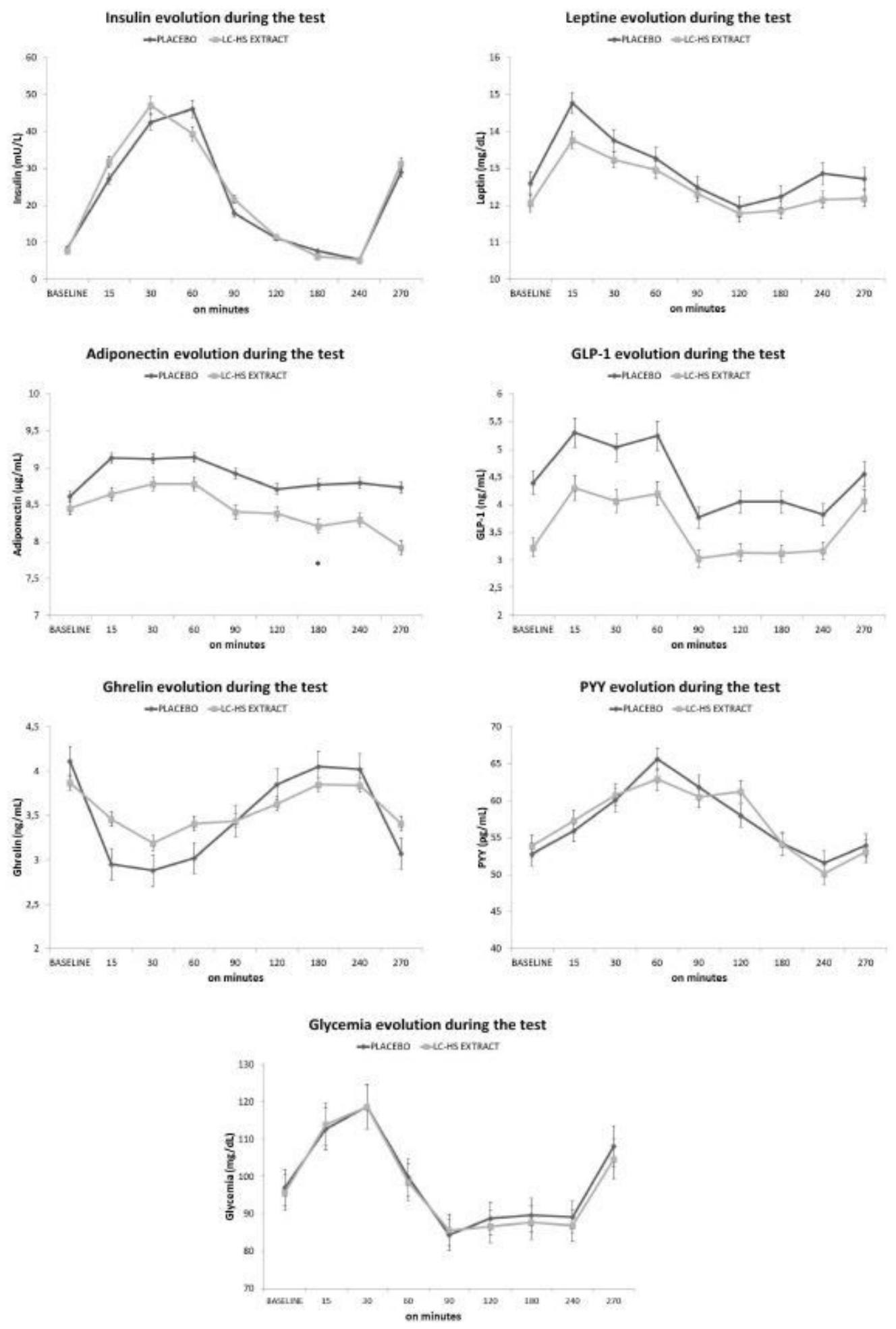

\section{Figure 9}

Hormones evolution during the test. * Means significant statistical differences between groups $p<0.05$. 


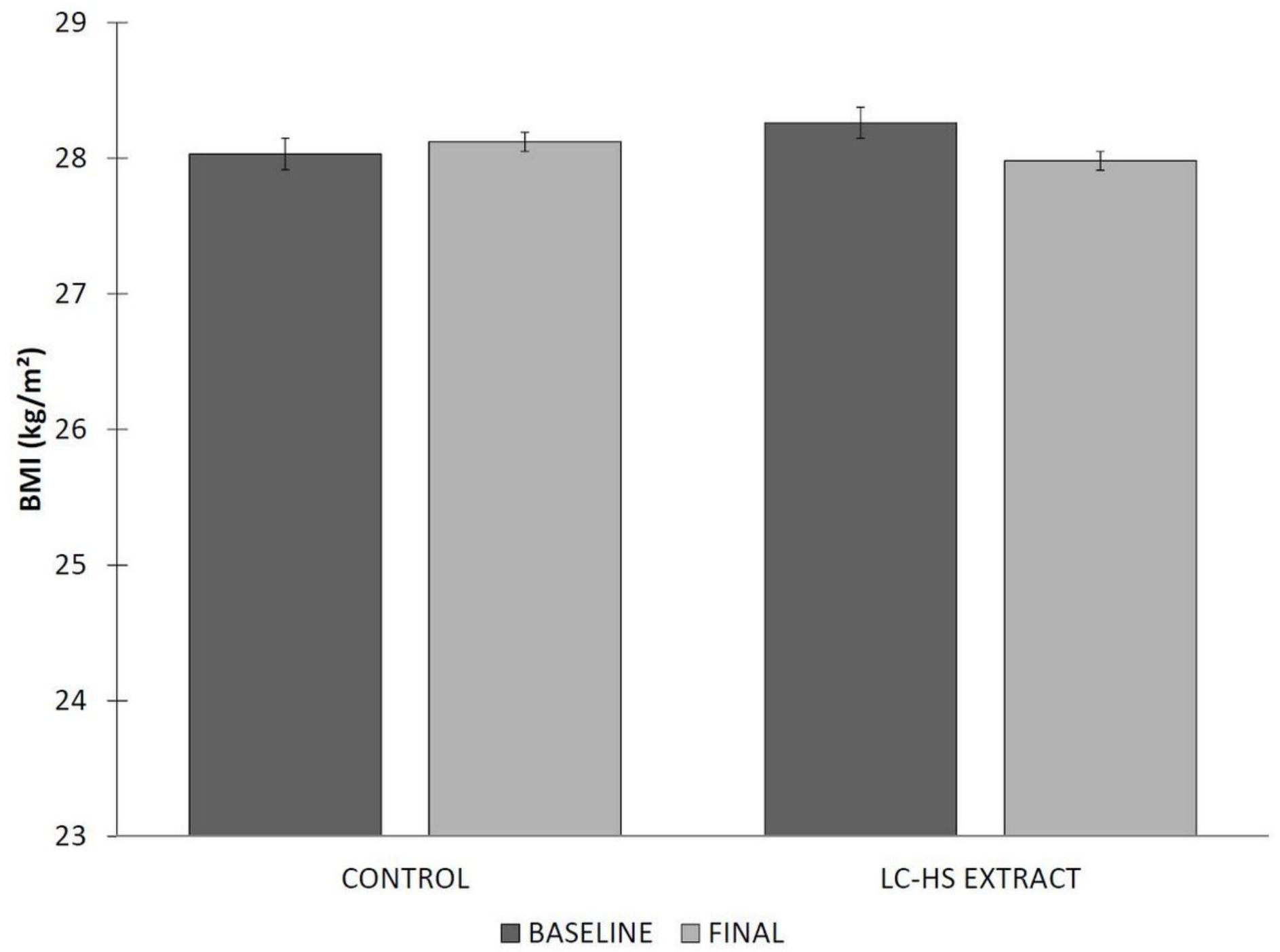

Figure 10

Body mass index $(\mathrm{kg} / \mathrm{m} 2)$ evolution during study. 


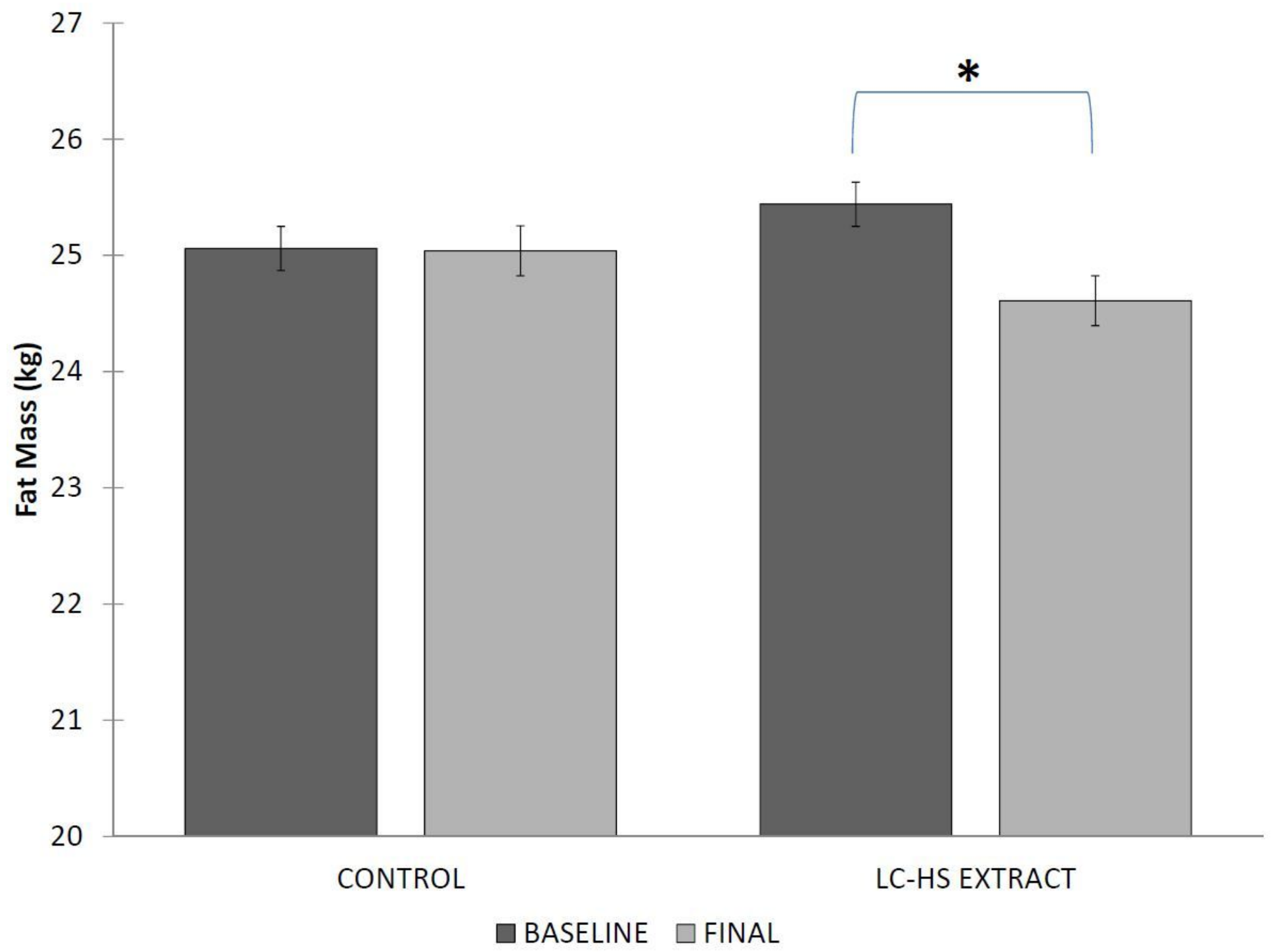

Figure 11

Fat Mass (kg) evolution during study. * Means significant statistical differences. 


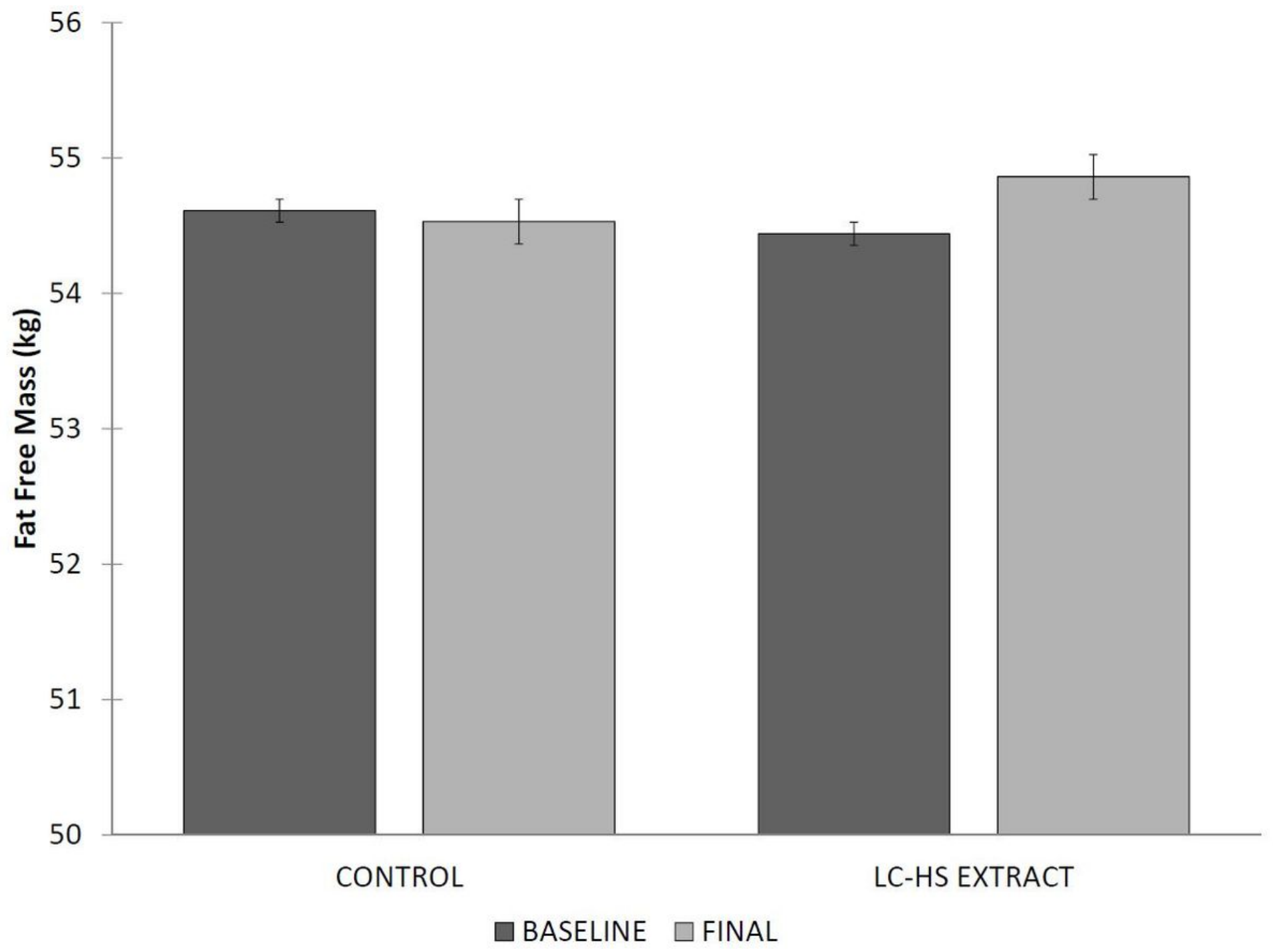

Figure 12

Fat Free Mass (kg) evolution during study.

\section{Supplementary Files}

This is a list of supplementary files associated with this preprint. Click to download.

- CONSORTEquity2017ChecklistRAS.docx 